\title{
A Review on Synthesis and Applications of Statin Family Drugs as a New Generations of Anti-Blood Medicines
}

\author{
Sajedeh Safapoor ${ }^{a}$, Hamid Yazdani ${ }^{b} *$, Parisa Shahabi ${ }^{c}$ \\ ${ }^{a}$ Department of Chemistry, Iran University of Science and Technology, Tehran, Iran \\ ${ }^{b}$ Department of Chemical Engineering, Payame Noor University, Tehran, Iran \\ ${ }^{c}$ Department of Physical Chemistry, Alzahra University, Tehran, Iran
}
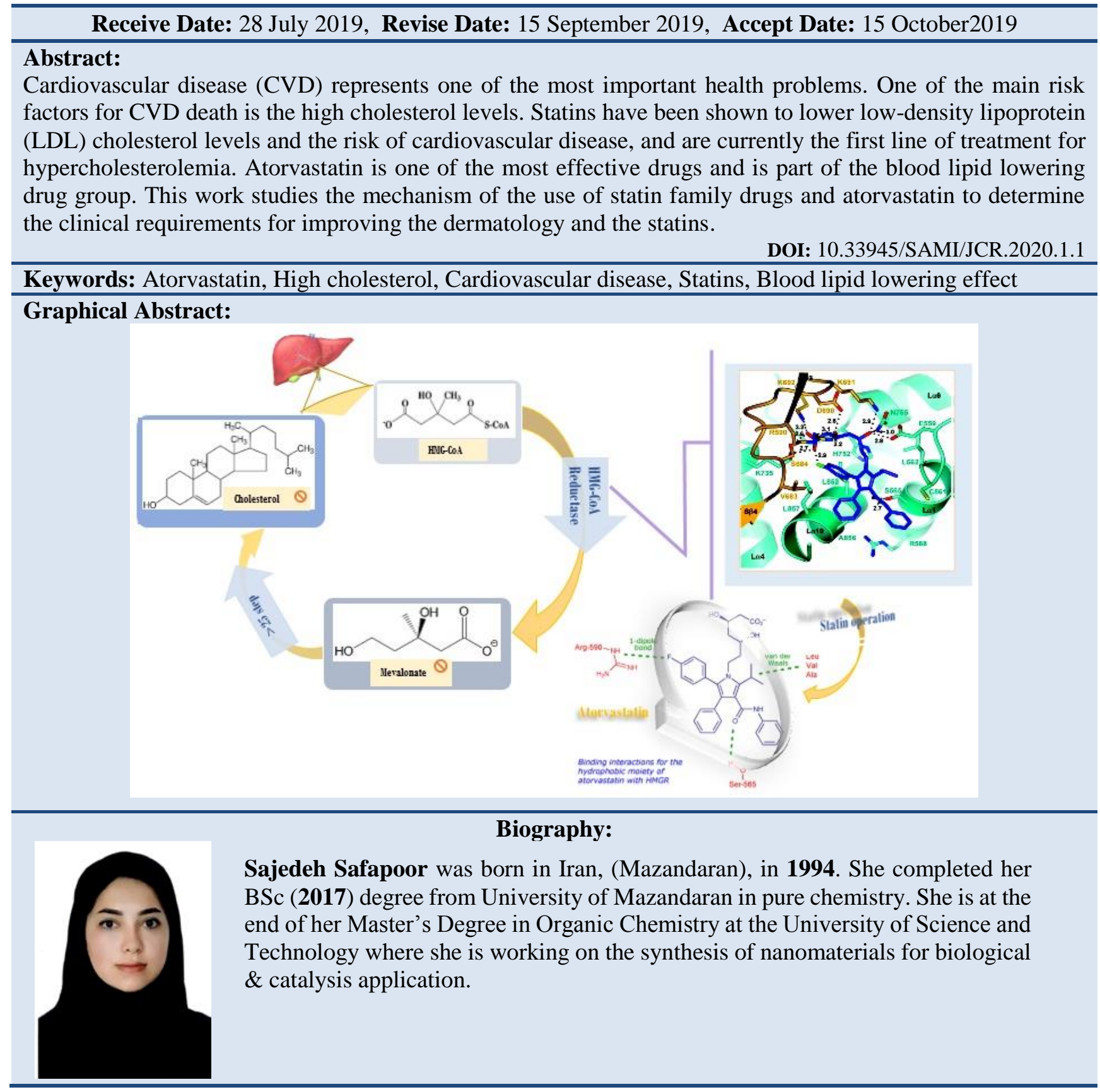

*Corresponding author: Hamid Yazdani, Email: h.yazdani@pnu.ac.ir 


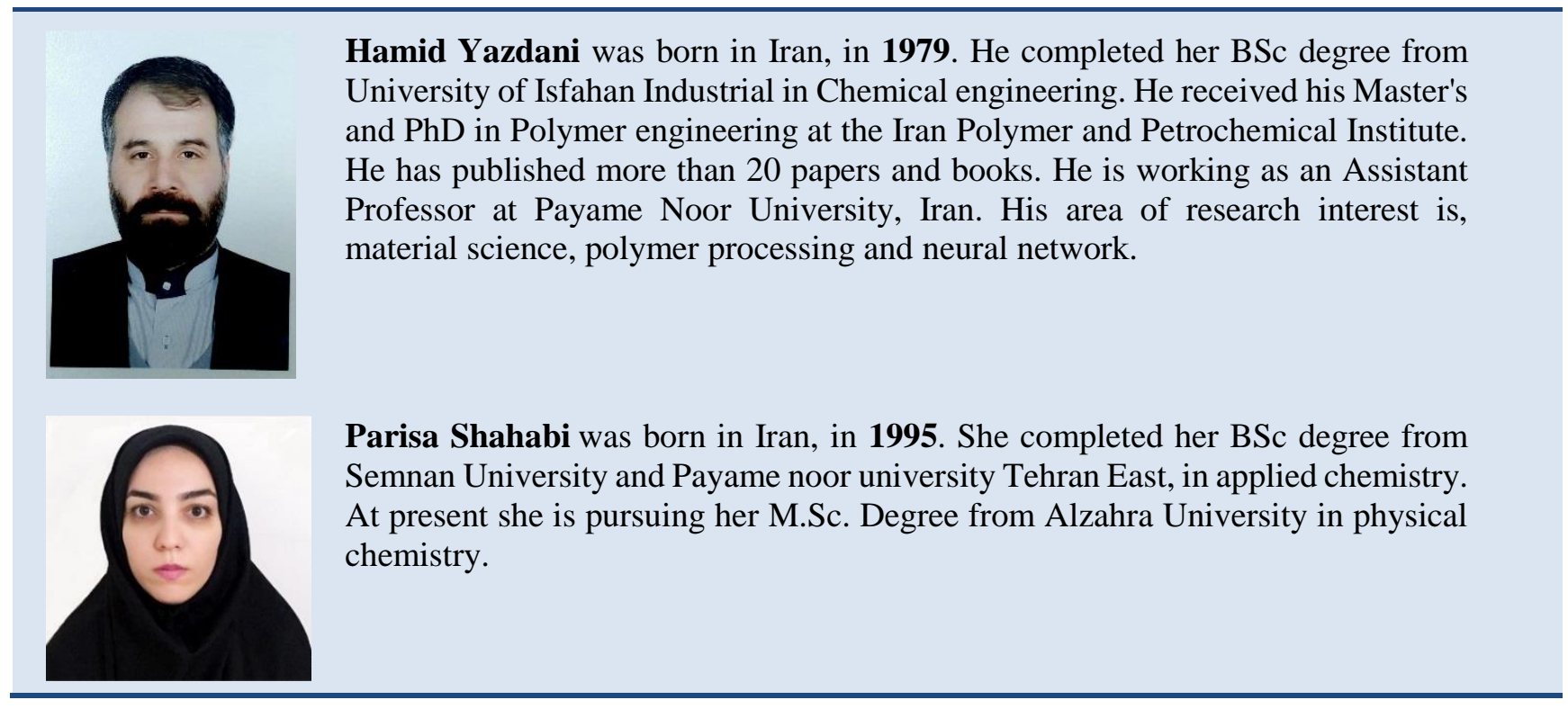

\section{Introduction}

Atorvastatin is a group of drugs that are known to inhibit 3-hydroxy-3-methyl-glutaryl-coenzyme a reductase or statins [1]. In the human liver, HMG-CoA is converted to mevalonate acid, which is a limiting step in the biosynthesis of hepatic cholesterol, by the enzyme HMG-CoA reductase. Inhibition of this enzyme diminishes the synthesis of de novo (Refers to the synthesis of complex molecules from simple molecules such as sugars or amino acids) cholesterol and increases the expression of low-density lipoprotein receptors (LDL receptors) on the liver's main tissue. This increase in LDL absorption by the liver cells results in lowering the LDL cholesterol levels in the blood [2]. As with other statins, atorvastatin also reduces the triglyceride secretion and increases the high-density lipoprotein (HDL). Atorvastatin calcium, the brand Lipitor $\AA$, is the first drug in the United States reaching an annual turnover of $\$ 10$ billion and is currently the world's leading pharmaceutical product. Recent studies have shown that in patients with the acute coronary syndrome, high-dose statin therapy may stabilize the role of platelets. Atorvastatin reduces stroke and heart attacks in people with type 2 diabetes and coronary heart disease [3]. The mechanism of action of atorvastatin is that it is rapidly absorbed from the digestive tract when taken orally. Absolute bioavailability of the drug is about 14\% [4]. This drug has liver and extrahepatic metabolism and the graft of the drug with the protein is very high. Liver is the main site for atorvastatin action, as it is the main synthesis of both cholesterol and LDL clearance. Active drug metabolizers are responsible for creating about $70 \%$ of the inhibitory effect of HMG_CoA reductase. The halflife of the drug is about $14 \mathrm{~h}$ and feces [5] intentionally excrete it.

This drug easily attaches to the protein, and studies have shown that it is likely to be secreted in breast milk.
Therefore, it is appropriate for children over 10 years of age. It is also strictly prohibited to be used during pregnancy [4]. Part X is classified and may cause fetal death or defect, with these interpretations being used to treat adults.

In some cases, atorvastatin or Lipitor can lead to a condition that results in the breakdown of skeletal muscle tissue and ultimately leads to renal failure. If you have muscle aches or muscle weakness, especially if you have unusual fatigue fever and dark urine, inform the doctor immediately [6].

Atorvastatin may be combined with bile acids and complexing agents, increasing the cholesterol-lowering performance. However, the concomitant use of cyclosporine, a fibrose antibiotic with atorvastatin, may increase the risk of renal failure and habdomyolysis, which is not recommended. The simultaneous consumption of grapefruit juice also may increase the plasma concentration of the atorvastatin [4].

\section{Statin}

Statin, known as 3-hydroxy-3-methylglutaryl coenzyme reductase inhibitor, is a prescription drug for reducing the cholesterol and is part of a group of lipid lowering-drugs [7]. Statin acts by inhibiting the enzyme mentioned above and required to produce cholesterol in the liver [8]. Without the help of that enzyme, your body cannot convert the fats that you consume into cholesterol. Excessive cholesterol circulation in your arteries is dangerous as it can make plaques that plaques prevent the proper flow of blood and increase the risk of a heart attack.

Strong evidence of statins for the treatment of cardiovascular disease in the early stages of the disease (secondary prevention) and those at high risk but without the cardiovascular disease [9].

Many types of statins are available and can be classified as follows: 
A. Different statins for the nucleus [10]

B. Different statins in terms of severity

C. In terms of the nature of production

Here is a review of them:

A.1 Statins of type I: The nucleus of this group of statins is the decalin ring. The resemblance to the first statin has been discovered so far. Due to their structural relationship, they are often classified as first-class statins. These statins, which ultimately extract from fungal metabolites, exhibit the following general structure, including compactin (Mevastatin), Lovastatin, Pravastatin, and Simvastatin (Figure 1) [11].

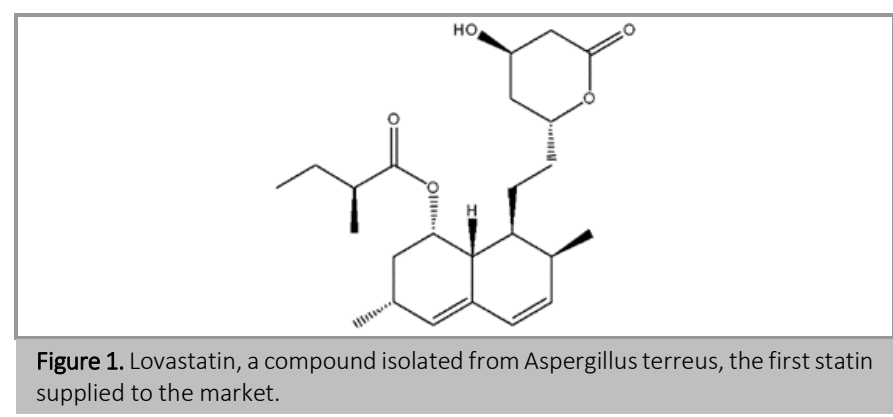

A.2 Statins of Type II: Type I statins have showed a very effective performance on lowering the cholesterol levels; however, adverse effects and difficult synthesis resulted in further optimization. As a result, structures derived from the type II statins in which the decalin ring was replaced by a larger hydrophilic section. This group of statins is synthetic and includes pitavastatin, cerivastatin, fluvastatin, atorvastatin, and rosuvastatin (Figure 2) [11].

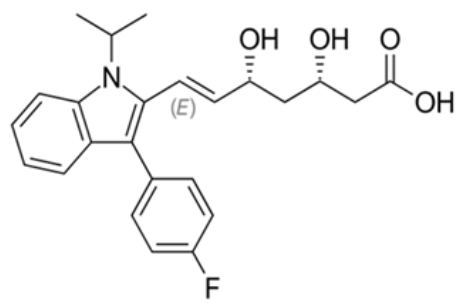

Figure 2. Fluvastatin, the second type statin with the central ring of the indole.

B.1 High-intensity statins such as atorvastatin (Lipitor ${ }^{\circledR}$ ) and rosuvastatin (Crestor $\left.{ }^{\circledR}\right)$, are the most effective drug in this class of drug for treating blood lipids [12].

B.2 Medium-grade statin such as fluvastatin (Lescol®), lovastatin (Altoprev ${ }^{\circledR}$ )

Pitavastatin (Livulo®), Pravastatin (Pravacholß), and Simvastatin (Zocor®).

C.1 Fermental derivatives: Some types of statins are naturally occurring and can be found in foods such as mushroom shellfish and brown rice [13].

C.2 Synthetic: such as atorvastatin, cerivastatin, fluvastatin, pitavastatin and rosuvastatin
Also,to improve the performance of the drug, statin combination with other drugs has been used, such as:

Vytorin: A combination of statin (simvastatin) and cholesterol absorption inhibitor (Ezetimibe), which slows down the formation of cholesterol by the body's cells, and, along with isitumb, reduces the absorption of cholesterol by $53 \%$ of the intestine.

Mevacor, lovastatin + niacin

Cduet, which combines statin (atorvastatin) and calcium antagonist (amlodipine)

Simcor, Simvastatin + Niacin

Regarding the patent expiry, many of the branded statins, including atorvastatin have been marketed since 2012. Although all of the statins act in one direction, your body may give a better response to one type of one another because physicians sometimes try a lot of statins to find the right type for you.

\section{Effect of Statins on Cholesterol}

Statins are a competitive inhibitor of the hydroxymethylglutaryl coenzyme reductase enzyme. 3-Hydroxy-3-methylglutaryl-Coenzyme is an intermediate in the pathway for the formation of mevalonate and ketone sulfate [14] (Figure 3). This compound is synthesized from acetyl coenzyme A and acetoacetyl coenzyme (Scheme 2).

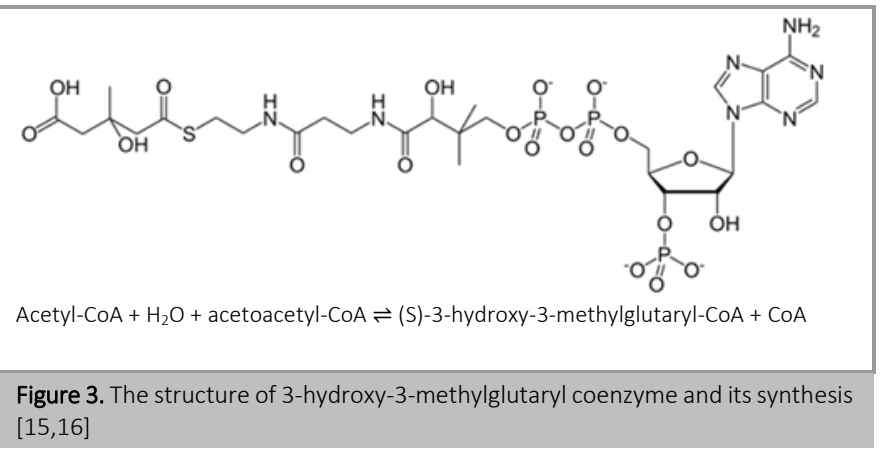

\subsection{HMG-CoA reductase enzyme}

Minor J. Coon Researches and Bimal Kumar Bachawat in the 1950s discovered this compound, HMG-CoA. An intermediate of metabolism in the metabolism of branched-chain amino acids is including leucine, isoleucine, and valine [15], [16].

More than 30 enzymes are involved in the biosynthesis of cholesterol, and this path has been identified over the decades to meet the needs. The enzyme HMG-CoA reductase, a synthetic pathway controlling the enzyme mevalonate, generates a metabolic pathway that produces cholesterol and other isoprenoids. Typically, in mammalian cells, this enzyme is stopped by cholesterol derivatives from the degradation of low dopant lipoproteins by LDL receptors, as oxidizing cholesterol spaces. Competitive inhibitors of reductase induce expression of LDL receptors in the liver, which 
in turn increases the catalytic metabolism of LDL in plasma. Therefore, this enzyme is the ultimate goal of widely available cholesterol-lowering compounds that are commonly known as statins. The main isoform of HMG-CoA reductase in humans is 888 amino acids long. This is a multifilament membrane protein, which consists of two main areas (Figure 4).

In the human liver, the reaction of HMG-CoA to mevalonic acid, influenced by the HMG-CoA reductase enzyme, is an essential step in the biosynthesis of cholesterol, thus, the competitive inhibition of this enzyme by static drugs reduces plasma cholesterol levels.

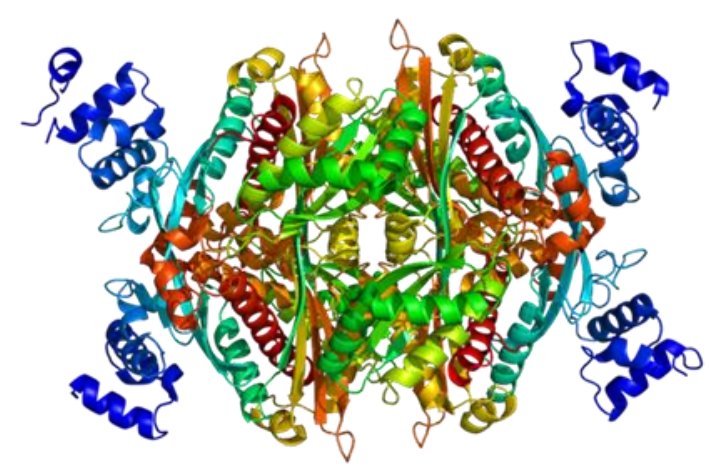

Figure 4. The structure of an HMG-CoA reductase enzyme

\subsection{Effect of statin on the pathway for biosynthesis of cholesterol}

Since statins with a structure similar to HMG-CoA are similar at the same molecular level, they can be located in the active site of the enzyme and can compete with the original substrate (HMG-CoA). This competition reduces the amount of HMG-CoA reductase that can produce mevalonate (Scheme 1) [17]. This molecule eventually produces cholesterol (Scheme 2). The metabolism pathway of mevalonate is a very important metabolic pathway in eukaryotes and many bacteria, which ultimately results in producing many important compounds such as cholesterol; isoprenoids (terpenes, such as lycopene, carotene, squalene, eucalyptol, and pinene).HMG-CoA reductase is activated when blood sugar is high.

The basic function of insulin and glucagon is to maintain glucose balance, therefore, in controlling blood glucose, indirectly affects the activity of HMGCoA reductase.

Nevertheless, the decrease in enzyme activity is caused by the protein kinase activated by adenoid monophosphate (AMP), which responds to an increase in AMP and leptin levels. HMG-CoA reductase is an important enzyme for growth. Inhibition of its activity and non-coordination of isoprenoids can be leading to a defect in stem cell migration and the intracerebral hemorrhage.

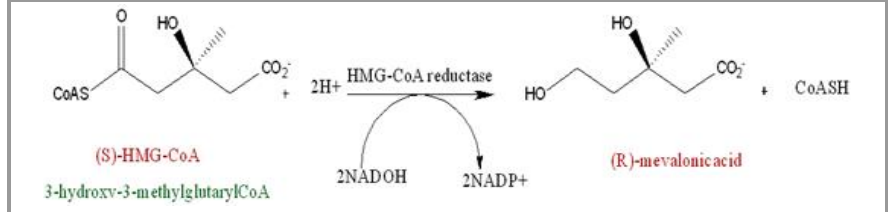

Scheme 1. The reaction of 3-hydroxy-3-methyl glutaryl coenzyme A to mevalonic acid [18].

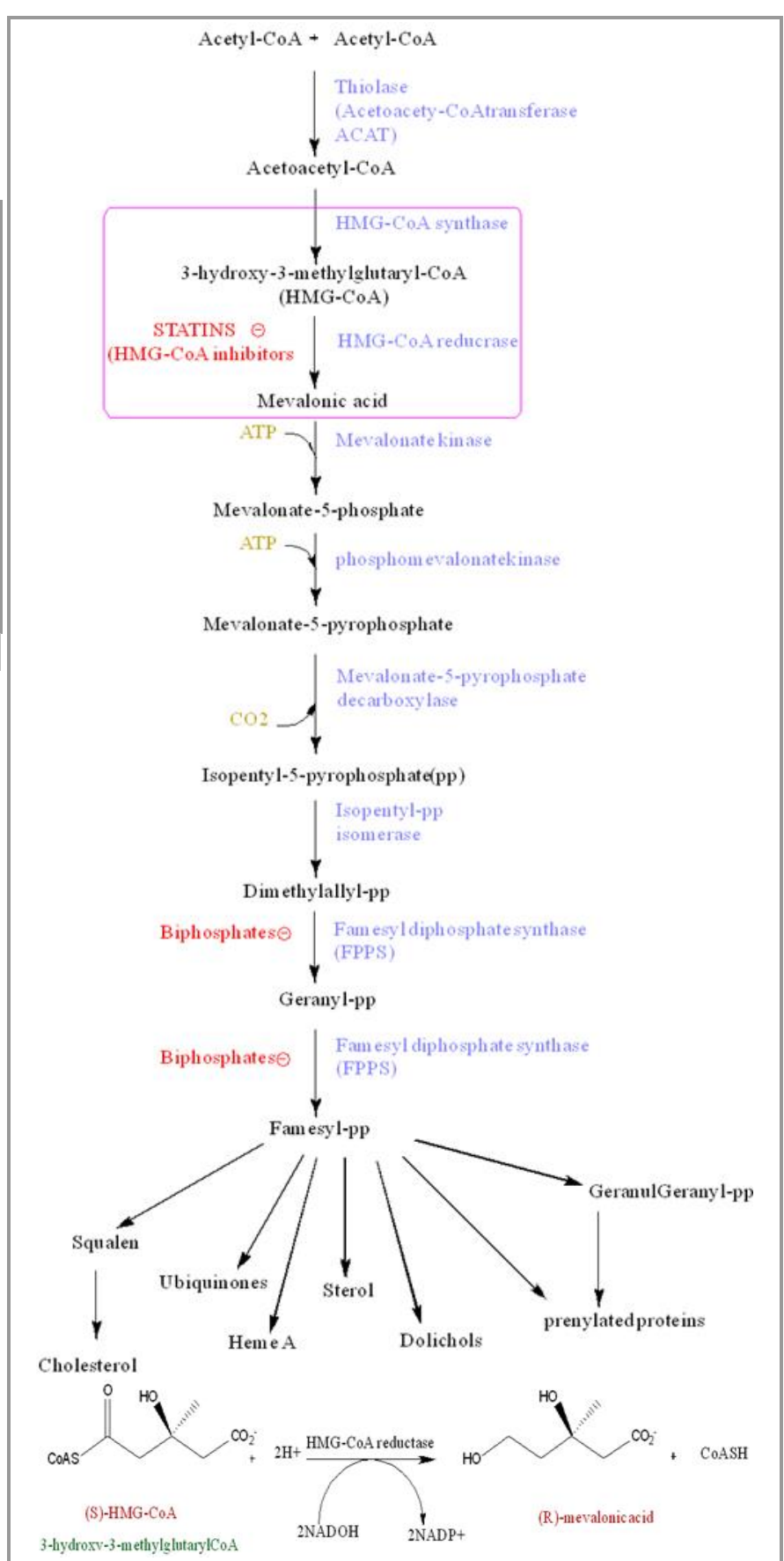

Scheme 2. Synthesis of mevalonate and the effect of statin on inhibition of cholesterol [20].

\section{Detection and introduction of atorvastatin}

The focus of research in the 1980s was to search for the potent inhibitors of the 3-hydroxy-3-methylglutaryl coenzyme reductase enzyme, which is in the phase of 
limiting the rate and the first step in the cholesterol biosynthesis pathway. With the discovery of inhibitors derived from the fungal metabolites, several of fully synthesized (synthesized) inhibitors, mevastatin, lovastatin, pravastatin, and simvastatin were discovered and developed. This study explores the discovery and development of one of those inhibitors called atorvastatin calcium currently marketed under the brand name Lipitor ${ }^{\circledR}$ (Figure 5).

This inhibitor was designed based on the comparison of the structural molecular models between the fungal metabolites and other derived synthetic inhibitors.

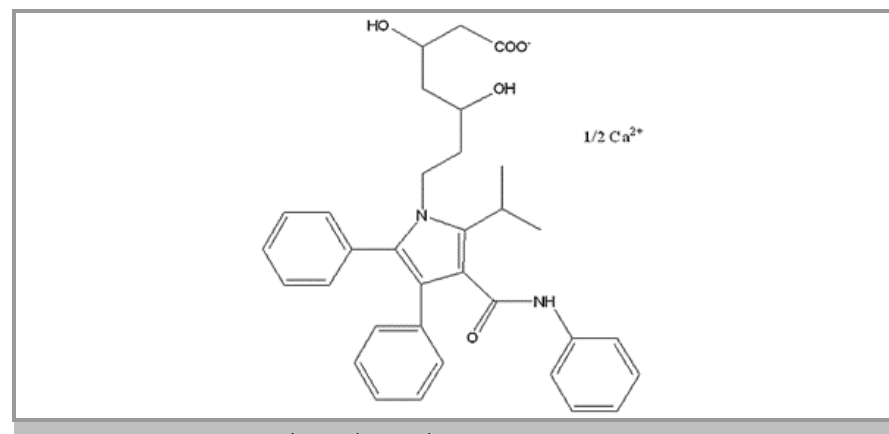

Figure 5. Atorvastatin Calcium (Lipitor).

In addition to develop the structural activity relationships that resulted in producing the calcium atorvastatin, another important aspect of the development of this sector is the improvement in chemistry that requires the elimination of the complexity of increasing the synthesis of compounds to inhibit the enzyme. Finally, the development of several chiral syntheses on atorvastatin calcium enantiomeric pure was carried out through a collaborative effort between discovery and development. The impact of the progress required in chemistry, as well as external factors, will be discussed in the internal decision-making on the development of atorvastatin calcium. Cholesterol biosynthesis of acetyl-coenzyme A contains more than 20 biosynthetic steps (Scheme 3) [19].

This pathway is strictly controlled and regulated by the number of LDL receptors on the surface of the liver cells that are used as a means of ensuring that the cholesterol in the body is kept constant [19]. From the late 1950s and early 1960s, inhibitors of biosynthesis of cholesterol proved to be effective in reducing the plasma cholesterol, both in humans [21] and in animals [22]. What was known was that this inhibition was easily accomplished. In fact, the first drug for this purpose was introduced by Richardson-Merrell called Teri Peranol (Figure 6).

There were many doubts based on the experience that Teri peranol causes blurred vision and cataracts in humans. However, the precise and effective criteria for inhibiting the biosynthesis of cholesterol were clearly expressed by Curran and Azamoff in 1957.

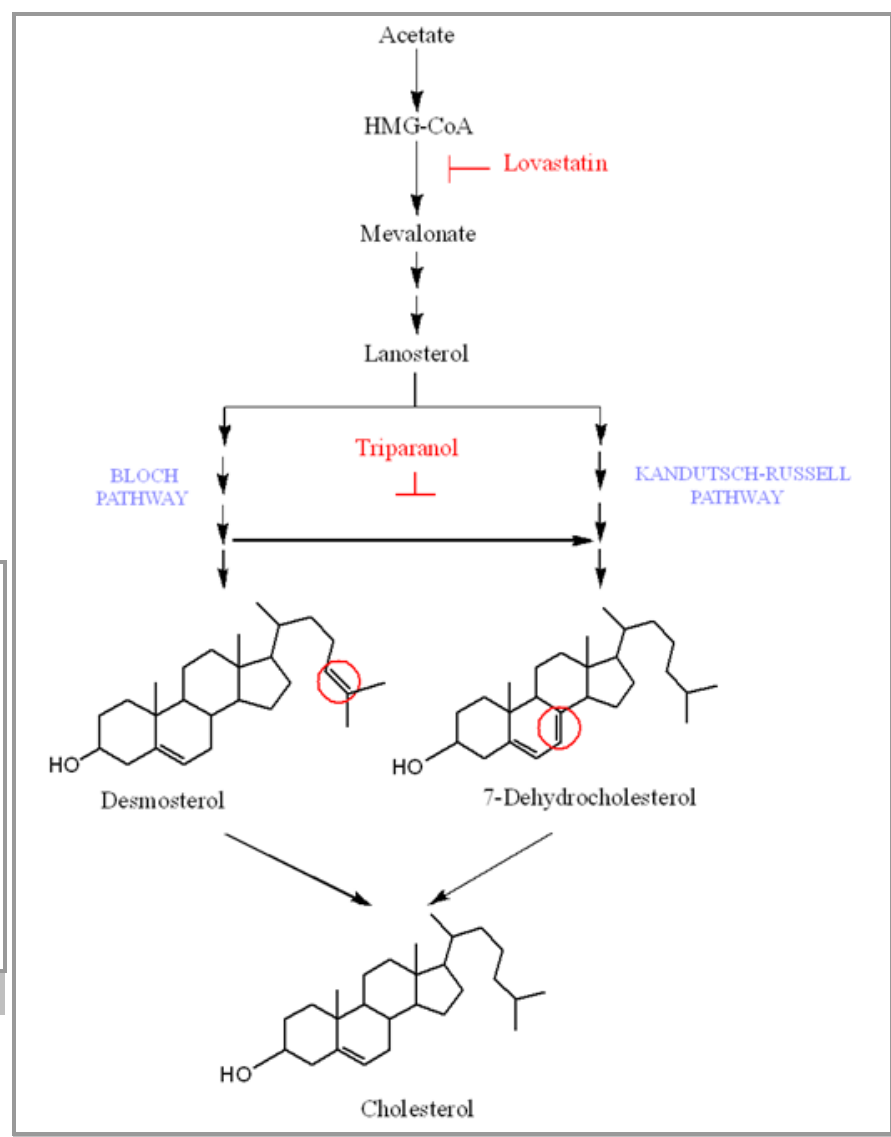

Scheme 3. Biosynthesis Route Cholesterol [23]

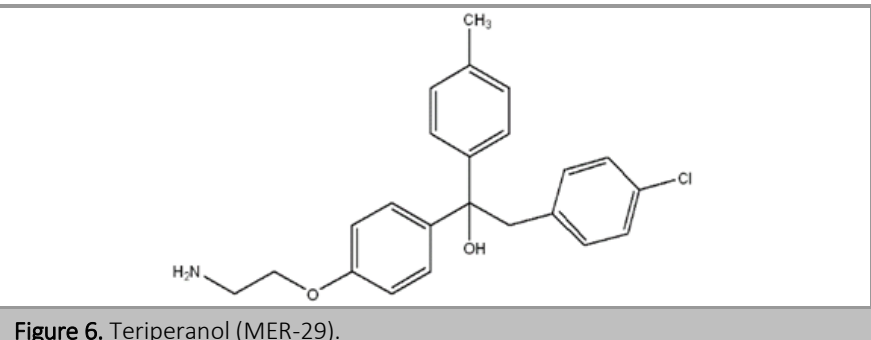

Figure 6. Teriperanol (MER-29).

They believed that containment could be achieved by blocking the path after formation of the acetoacetate, and before we formed the scalene, when deep mechanical studies were done on teriperanol. Not surprisingly, it was discovered that this rule was corrected by controlling the pathway in the pentolytic production in the pathway of biosynthesis, with the accumulation of desmesterol in the plasma and the tissue of patients treated with this drug (teriperanol) [24]. Further studies have shown that desmesteroll is also accumulated in the patient's lens.

In teriperanol, it only prevents the synthesis of cholesterol in the body from the very last stage; however, still desmestrol, which results in blurred vision in the eyes, is produced as biosynthesis. In spite of the findings of the trial of Teri peranol, the search for cholesterol biosynthesis inhibitors continued and hoped that pre-scleral inhibition would prevent intramammary intermediates, such as risperol, and an outcome for the treatment of hypoclostolemia [25]. The 
enzyme is located in an endoplasmic reticulum membrane and catalyzed (S) -3-hydroxy-3methylglutaryl coenzyme A into 3- (R) -malonic acid via a Hemi-thio acetal in a two-stage conversion (Scheme 4).

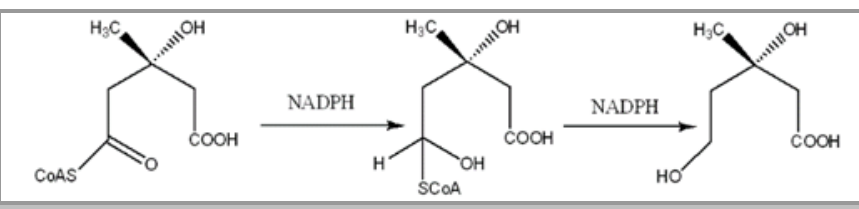

Scheme 4. Reduction of HMG-COA catalyzed by HMGR

Given that this hemiacetal is the most similar to the structure of an intermediate in the transition state, it is not surprising that the composition of the beer fermentation process has a structural similarity to it. Scientists also inspired the work of Louis Pasteur, who worked on microbial culture and 6,000 microbial metabolites, to identify the first product in the fermentation process at the same time in two distinct labs, named after Compactin [26], but later Renamed Mevastatin. This compound, which was the first effective ingredient in lowering cholesterol, is, in fact, ring lactate (lactone).

The second combination of fetal studies by Sankyo Corporation was obtained from the Penicillium Citriniume medium, which turned out to be a strong inhibitor of HMGR and competitive with other compounds in rat liver and sterol synthesis in the body [27]. Shortly after the discovery of Compactin, the second fungal metabolite in the methyl group with mevastatin was found to be present in the Aspergillus trius culture by Merck Company employees (called Mevinolin) [28] and in the Monascus Ruber by the Sankyo group (Monacolin [29].

The effect of this compound on the rat liver was twice as high as mevastatin; later this compound was named lovastatin. Eventually, this combination was the first HMGR enzyme inhibitor that was approved by the US Food and Drug Administration for the treatment of hypercholesterolemia and was marketed by Merck SHARP and Dohem with the Mevacor® brand. Two other strong inhibitors of fungal metabolites and finally the market for drugs were produced, pravastatin (4) was produced by hydroxylation of the microbial mevastatin compound, and simvastatin (5) was synthesized by formation of the lovastatin [30]. Although all of these compounds are strong inhibitors of HMGR and are one of the effective factors in lowering cholesterol, concerns in the 1980s were due to the end of compacting development, as the results of clinical trials of toxicology created security concerns that delayed the development of lovastatin.

Therefore, although fungal metabolites were considered as a class and showed clinically relevant clinical trials, in the early 1980 s, new structures were created to inhibit HMGRs, so that toxicity was unrelated to their mechanism of action (Figure 7).
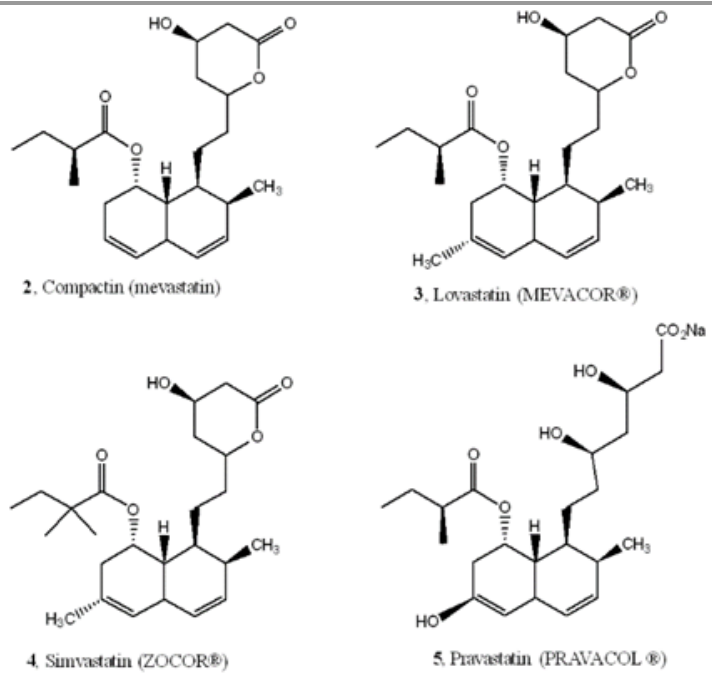

Figure 7. Fungal metabolites inhibitors of HMGR

The first results in this regard showed that a simpler ring should replace the hexahydronaftalin section of the fungal metabolites without losing its biological activity () [20]. To begin with, the Pyrrole loop system was used, which mainly consists of 1 and 4 diketones during the Paal-knorr condensation [31] (see Recapture Synthesis in Scheme 5).
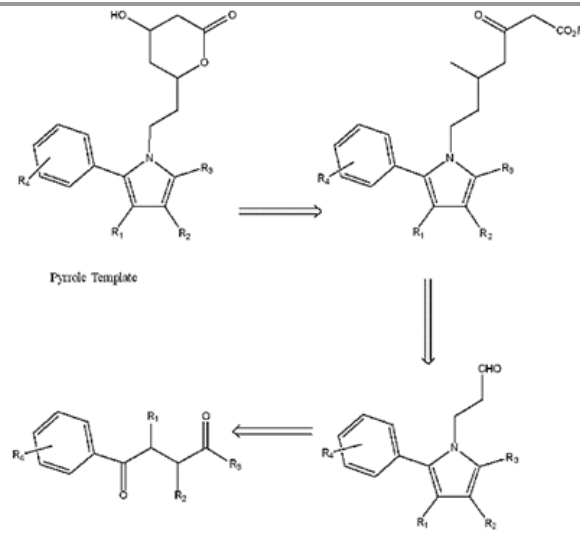

Scheme 5. Pyrrole inhibitor re retrosynthesis.

This design was very effective in practice, and a large number of 1, 2, and 5-pyrrole-3 substitutions were prepared. Unfortunately, this method introduced the 5hydroxyl chemistry as a mixture of racemic, but this problem was solved by selective reduction of the Phydroxyl ketones compounds and by Narasaka and pai developed [32] and in general, diastereomers were obtained with a ratio of 10: 1 anti/syn. Finally, the corresponding lactone was obtained by refluxing in toluene and removing the diastereomer cis by Crystallize.

Trans-pure diastereomer opens with hydrolysis to form dihydroxy acids with the biological activity of the ring (Scheme 6). 


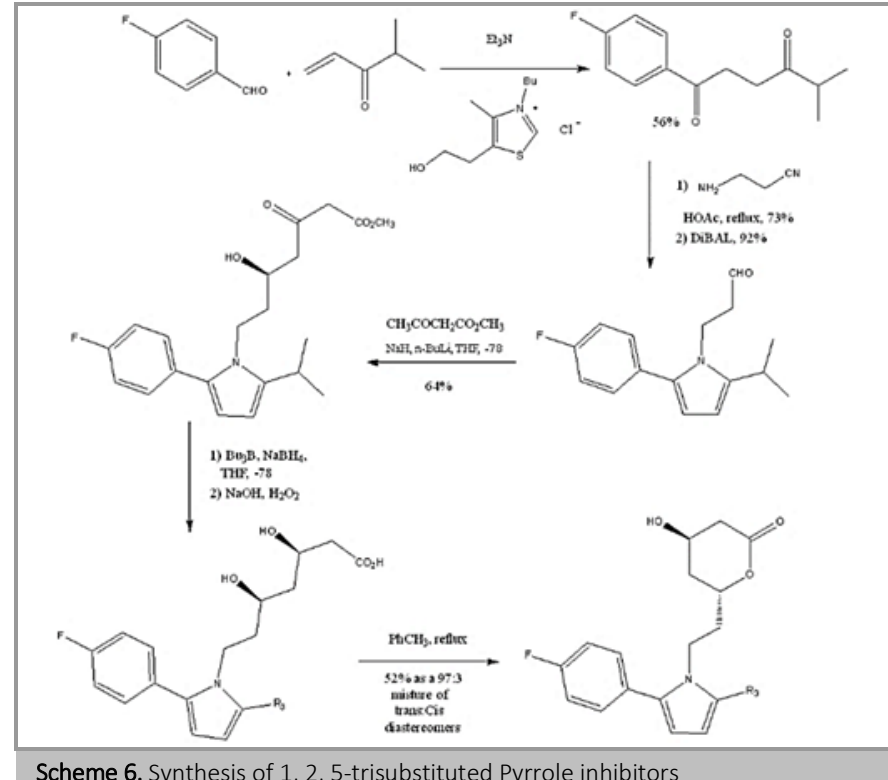

Scheme 6. Synthesis of 1, 2, 5-trisubstituted Pyrrole inhibitors

Unfortunately, this compound has only one-tenth of the strength of mevastatin is inhibition. Given that all biological activity is present in an Isomorphic, we still have no significant ability to achieve this goal. In this case, the options for finding the category of new combinations are narrowed.

Through experiments and reactions performed to replace the various substitutions in the 3rd and 4th positions of the various analogs Pyrrole rings, the strength and compositional toxicity of the compounds were studied; for example, one of these analogs is the four- stroke 1, 2, 3, and 5, using Strict Chemistry, we could replace the cinemal ester after de-carboxylation (Scheme 7).

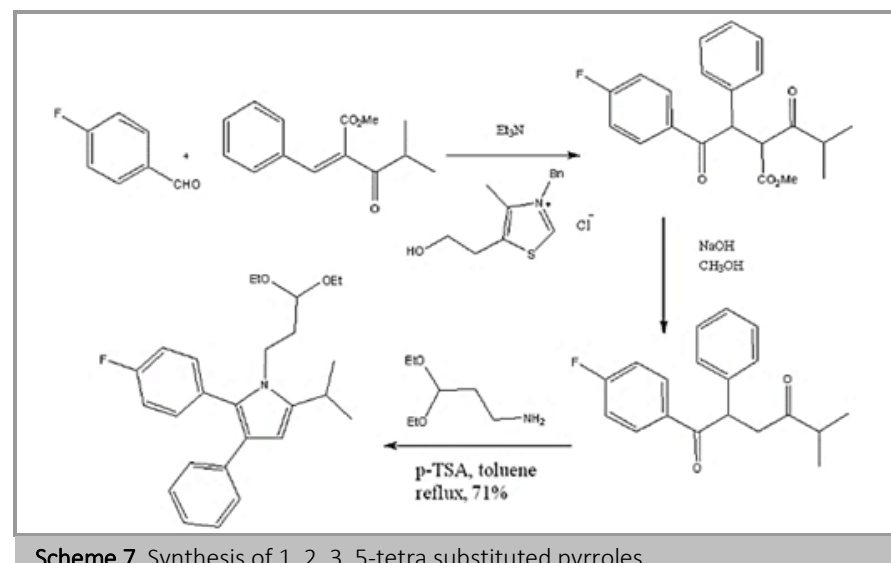

\section{Preparation of Atorvastatin}

Due to the difficulty of synthesizing these stroke compounds, only 20 analogues were obtained and the best activity among the analogues was observed in 3phenyl, carboxyamidophenyl-24. After hydrolysis and separation of the two enantiomers of the compound, 24, as we expected, all of the biological activity was observed in a stereoisomer (+) -24 [40]. Later it was found that this isomer compared with the simvastatin was more potent inhibitor in laboratory conditions.

Also, on a larger scale and in-body tests, lovastatin showed greater suppression in inhibiting hypercholesterolemia. In subsequent studies under more precise and controlled conditions with larger organisms, it was determined that atorvastatin is a potent inhibitor of HMGR in reducing LDL cholesterol in rabbits and guinea pigs, as well as reducing triglyceride in rats. We decided to develop atorvastatin as a pure enantiomer for several reasons:

1. Avoiding extra burden for the patient, that is, if the use of the racemic mixture of atorvastatin is used, 50\% of the inactive substance enters the patient's body, which reduces the metabolism of the drug to half.

2. The tendency to reduce apparent defects (such as drug strength) in a compound that has been introduced 10 years after inhibitors derived from fungal metabolites.

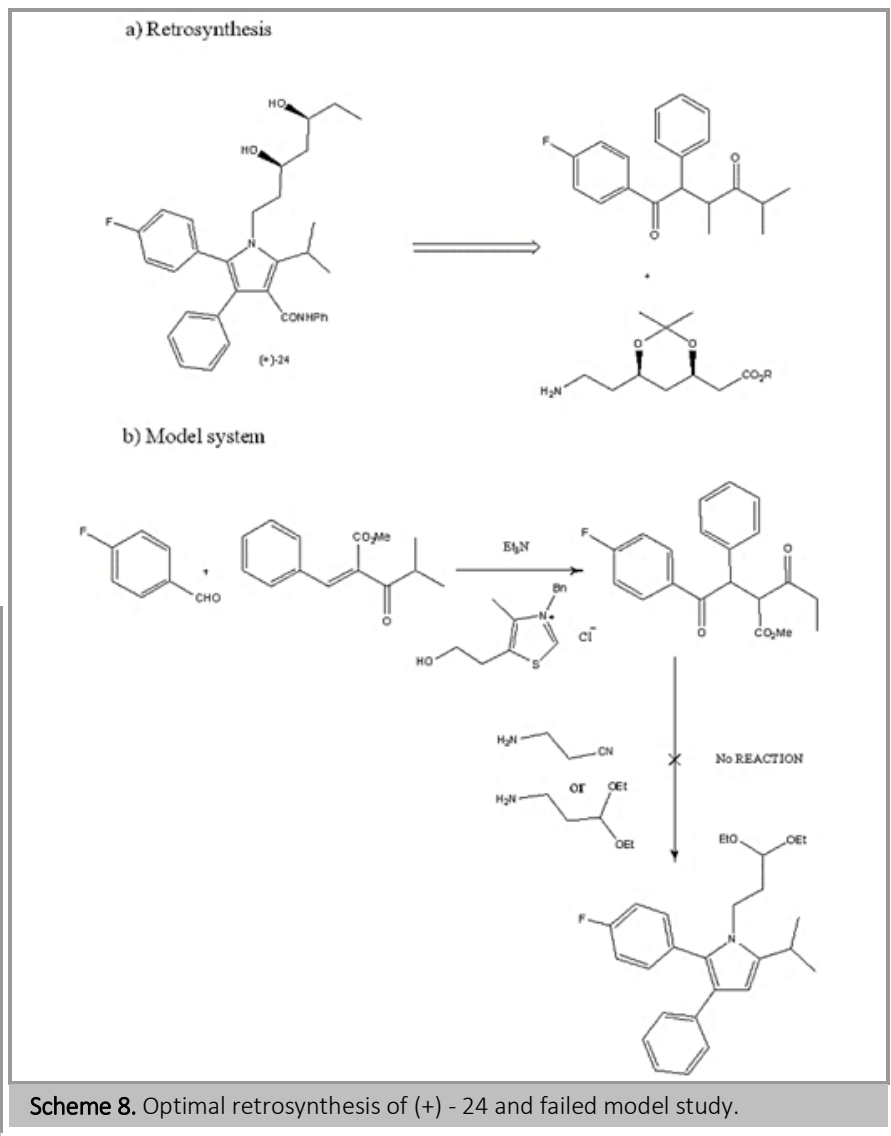

After that, it was decided to combine two different teams simultaneously and parallel to a chemical synthesis from the non-circular sector. One of the initial problems was the scale-up of the $3+2$ ringing reaction that was previously used; in this case, additional phenylamido-carbonyl phenylacetylene was needed to achieve good yields, but it was very difficult to get this product on a large scale. To come Conceptually, the solution to this problem can be by using the Paal-knorr that if one good amine can be 
properly replaced with 1,4 diketones, then cyclodehydrate. This path can also create the possibility of close synthesis using a fully developed side chain.

So, we used the Stetter method to prepare 1,4 diketones, although we were disappointed because we were not able to achieve the desired hydration in different conditions (Schemes 8). Because of our inability to influence the Paal-knorr condensation with fully substituted diketone, as an alternative, We tested the synthesis of the four stokes of the Pyrrole (Scheme 9).

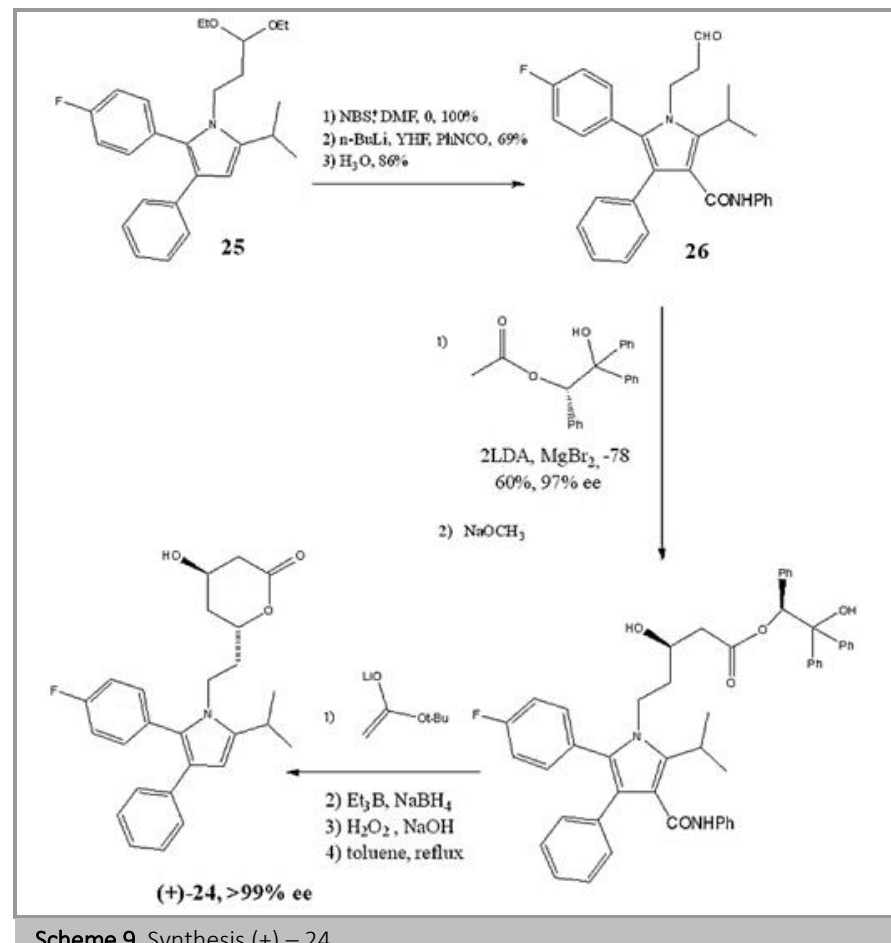

Scheme 9. Synthesis $(+)-24$

Subsequently, N-phenyl carboxamide was introduced, which was slowly prepared by $\mathrm{N}$-bromo-succinimide bromination after exchange of litium halide and the reaction of litium heteroaryl with phenyl isocyanate. Then, through hydrolysis, aldehyde 26 was prepared, which was previously prepared using an augmentation ring reaction of $[3+2]$. All of these changes can be made on a high scale and acceptable returns.

Thus, the density of 26 with magnesium dianide from S - (+) - 2-stooxy-2,1,1-triphenyl ethanol provides a ratio of 96: 4 of S, R and S, S diaterms in a $60 \%$ yield. This ratio improves with a re-crystallization time to 98 : 2.

The exchange of methoxy tert-butyric acid in reaction with an additional litium ter-butyl acetate, an R- $\delta$ hydroxy- $\beta$-ketoestro compound previously prepared as a racemic. The reaction with $\mathrm{Bu} 3 \mathrm{~B}-\mathrm{NaBH} 4$, which previously provided $\operatorname{cin}-\beta$ - $\delta$-dihydroxy ester, is obtained after hydrolysis, acidification and lactonization, pure lactone (+) -24 . Fortunately, crystallization is carried out without ethyl acetate / hexane and the $100 \%$ enantiomeric purity for $(+)-24$ can be obtained from the initial solution.

However, due to its linear nature, this pathway has been successful in producing pure enantiomeric compounds in grams and has included a number of low temperature reactions.

It also has relatively low yields in some of the final stages for final purification, but this pathway has a high potential for large scale and high $\mathrm{Kg}$ and requires little improvement.

For this reason, the Holland Group had to adopt a different approach [33]. One of the major components of this effort was a broad study of the Paal-knorr condensation by Alan Miller at the Chemical Development Company, which successfully applied a cyclodehydration to the model system when using a full eq pioalic acid as a catalyst (Scheme 10). Finally, a pyrrole 5stokes 27 was produced at $43 \%$ efficienc which is currently the ultimate goal in this synthesis.

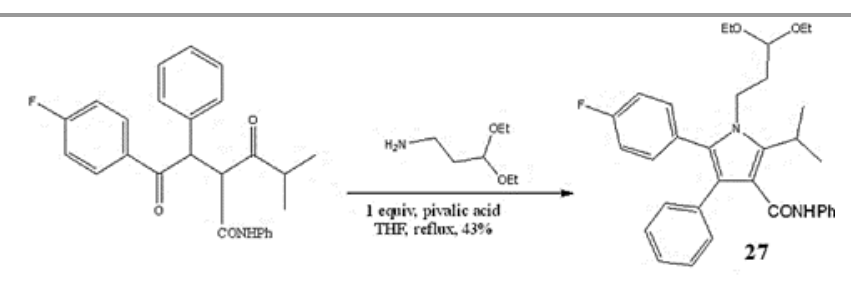

Scheme 10. Paal-knorr Synthesis of pentasubstitu pyrroles.

At the end of this study, several routes for the identification of (S) -methyl 1, 4-Bromo-3hydroxybutyrate 28 , an intermediate used in the previous synthesis, were used to control the HMGR. A key intermediate that is much more efficient than ascorbic acid, as previously reported, solely derived from stereoisomer (Scheme 11).

Protecting 28 as an intermediate of the tert-butyldimethylsilyl ether after converting to nitrile provides a more advanced 29-intermediate that can be obtained from several paths; therefore, 29 can be converted to hydrolysis by acid and through activation with $\mathrm{N}, \mathrm{N}$ Carbonyl di-imidazole develops after the reaction with

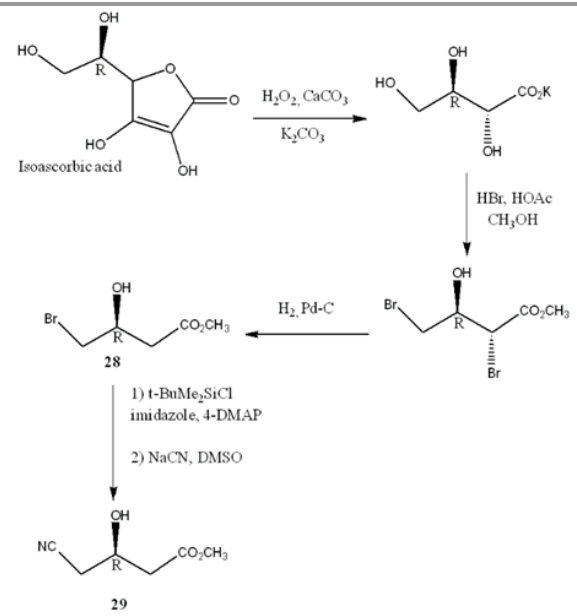

Scheme 11. Synthesis of (S) -methyl-4-bromo-3-hydroxybutyrate 28 
magnesium salts, potassium tert-butyl malonate [34]. Provides a diasteroselective in the range of 100: 1 . With recrystallization, this ratio is improved to 350: 1 . The reduction of nitrile with nickel-doped molybdenum ultimately provides a 32 -member side chain with an enantiomeri addition of over 99.5\% (Scheme 12)

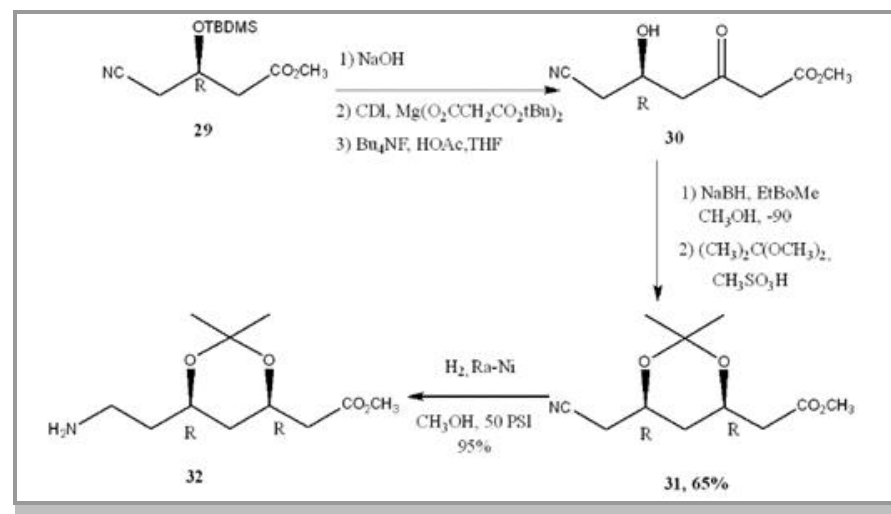

Scheme 12 . Synthesis of chiral side chains.

There is a shorter route to the preparation of the compound 30, which includes the reaction of an alcohol derived from 29 with 3-4 equivalent from lithium tert-butyl acetate to prepare hydroxy ketone 30 at a yield of $75-80 \%$. (Scheme 13)

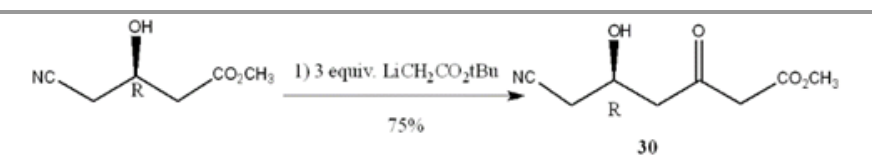

Scheme 13. Replacement Chain Synthesis.

Fully functional ligament cleavage ring 32 , with pure stereochemistry, complete with complete diketone stoke precisely defined conditions (1eq pivalic acid, 1:4:1 toluene / heptane / THF, Scheme 14), Pyrrole 33 in Returns up to $75 \%$.

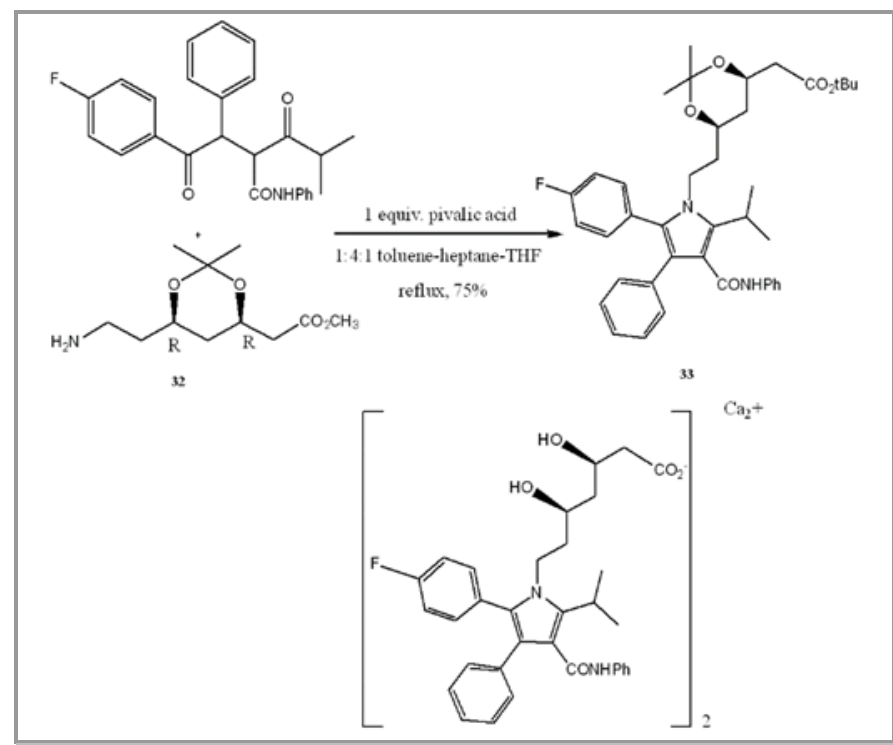

Scheme 14. Convergent, Chiral Synthesis of Atorvastatin Calcium.

Reducing the protection and formation of hemic calcium salt, space chemistry of pure atorvastatin calcium in a convergent and acceptable commercial way, which is the main prospect for the synthesis developed in the chemistry of the discovery but in practice reduced to chemical development.

Although you might expect the clinical improvement of atorvastatin calcium and imagine this forward, this was not the case. Over time, we completed preclinical studies and needed a case filed by the New Drug Application (IND) and the Food and Drug Administration (FDA) in late 1989, Mevacor®, Zocor ${ }^{\circledR}$, and the FDA had approved all Pravacol ${ }^{\circledR}$ for marketing. Therefore, we expected that atorvastatin drug to be marketed nearly a decade after at least three HMGR inhibitors and more. Fortunately, at this time, evidence of clinical efficacy studies began, suggesting that atorvastatin calcium may be a potent inhibitor or more efficient than cholesterol-lowering LDL and cholesterol than those that are derived from fungal metabolites, at least in some animals [35].

\section{Newer methods of atorvastatin synthesis}

\subsection{Atorvastatin Biocatalysts Synthesis}

This section explores different methods of synthesizing atorvastatin including, biocatalysts synthesis by various enzymes. Atorvastatin has a side chain containing two chiral centers in the drug delivery of its molecular structure. It can even be used for chiral precursors, through the use of metal catalysts or preferably by the use of free or immobilized enzymes and biocatalytic cells for asymmetric synthesis or racemic dissociation.

In bi-catalyst synthesis, chiral intermediates use a wide range of biocatalyts, such as alcohol dehydrogenase, 2deoxy-D-ribose 5-phosphate aldolase, nitrilase, and lipase.In inhibiting the enzyme reductase, the reduction of HMG-CoA to mevalonate, which is a limiting step for the initial rate of cholesterol biosynthesis is reduced, resulting in a decrease in LDL cholesterol levels.

Mevalonic Acid is a producer of terpenes and steroids, which has a chiral structure that enantiomer (3R) has drug activity. Atorvastatin is a side chain with two chiral centers (3R-5S) -dihydroxyhexanoate, resulting in its intermediate synthesis in a competitive reaction with $99.5 \%$ ee and $99 \%$ de [23]

The synthesis of this type of interfaces is done in a general way for the first time from an intermediate combination of 4 which has a hydroxy group of absolute configuration required. (Scheme 15) was then performed by performing a selective reduction of Sin [36] and after being protected from the hydroxy group, an isopropyl DN protected structure 2 with two centers Estrogenic is observed. Intermediate 2 is the main structural block for atorvastatin, as for other statins such as pitavastatin, rosuvastatin. From the discussion above, it is clear that the key step in the synthesis of the 
atorvastatin side chain is the intermediate synthesis of chiral 4 . This structure was previously synthesized by chiral compounds such as maltodextrin [37], L-maleic acid, or by synthesized asymmetric synthesis by the ruthenium and rodium complexes.

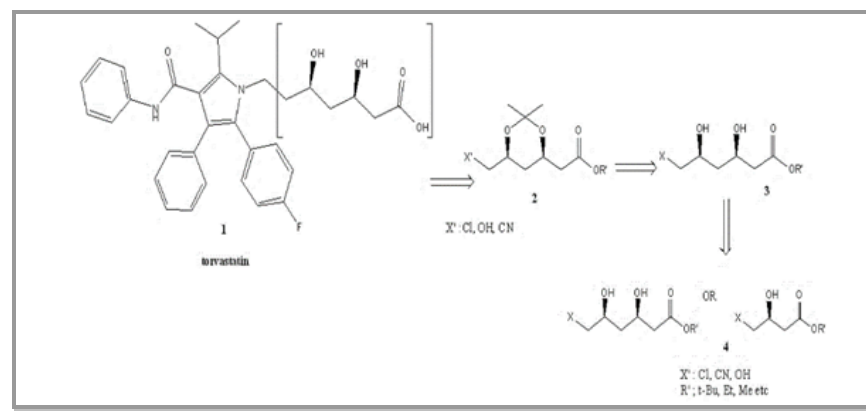

Scheme 15. Atorvastatin stage fragmention

All these common approaches have some problems including, the high cost of catalysts and severe reaction conditions such as having a metal catalyst or the number of process steps, as used for the synthesis of chiral compounds.

Also, an attractive strategy is the use of asymmetric enzyme catalysts in a kinetic reaction or solution in the synthesis for the desired intermediate, namely, Compound 4. Because of the natural selection and placement of high biocatalysts, formation of the lateral products has decreased. Also, most enzyme processes usually act in the environment; this reduces consumption energy by using the traditional synthesis methods. Thus, biocatalyst synthesis methods are more likely to be green than the conventional synthesis methods, and this greediness of biocatalysts Increases the acceptance of this strategy in the industry, as well as some of the biocatalyst processes that can be mentioned, such as Lactobicillus kefir (L Kefir) [38] Or Acinetobacter sp [39]. Generally, the biotal cell directly produces intermediate 3 by having two stereogenic centers with hydroxyl groups of the configuration required. Biocatalysts synthetic method for atorvastatin intermediates uses a wide variety of biocatalyst such as dehydrogenated alcohol, aldolase, nitrilase, lipase, halohydrin dehydrogenase and each of the catalytic processes of enzymes are described in the following section.

\subsubsection{Alcohol dehydrogenase}

Wolberg et al. [40] reported a new method for the synthesis of hydroxyketosters 6 (Scheme16), a precursor to atorvastatin, using the alcoholdehydrogenase enzyme Lactobacillus Brevis. This enzyme was used in E.coli and then cell extraction for biocatalyst reactions. The synthesis of 6 was carried out on a hot scale using a large amount of antigenic selection and Enantioselective and a reduction of keto ester 5 catalyzed by NADP $(\mathrm{H})$ dependent on alcohol dehydrogenase. Di keto ester 5 at position $\square$ (carbon 5) is reduced by the enzyme specifically to the hydroxy keto esters 6 with additional enantiomeric content of over $99.5 \%$, and the yield of the obtained product is $72 \%$ during the reaction time of 24 hours. Alcohol dehydrogenase itself can recover its cofactor via 2propanol to acetone oxidation, hence the recovery of the cofactor from the need for additional enzymes. Oxidation of 2-propanol is thought to stimulate the driving force of the desired reaction. Hydroxy Ketoester 6 can easily be converted syn to dimethyl hydroxy ester by selective reduction of the cinnamon and can be synthesized by increasing the number of protection steps, intermediate 8 .

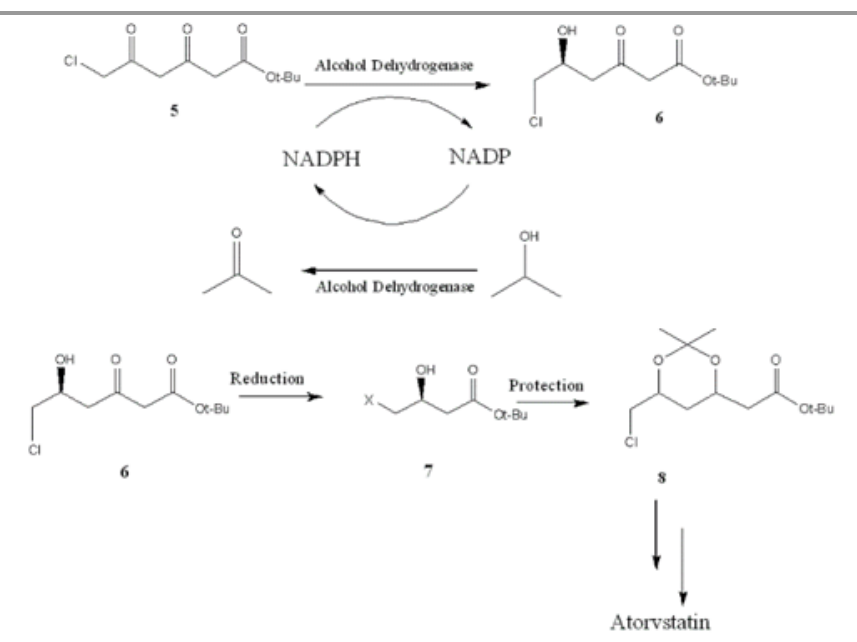

Scheme 16. A New Synthetic Route for Keto ester 6 by Wolberg et al.

The synthesis of the central chiral atorvastatin site is further investigated. This process is increased by a total of 24 hours, using a discontinuous fed-batch reactor with a yield of more than $90 \%$ in a total reaction of 100 gr.

Another approach for the synthesis of Compound 7 (Scheme 17) was by using L.Kefir as whole cell Biocatalyst [38]. It has been determined that this organism consists of two different types of alcohol dehydrogenase, which in the selection and selection selections of the high composition 5 was converted to dihydroxy-ketoester 7 by the intermediate 6 . The cofactor $\mathrm{NADP}(\mathrm{H})$ is recovered by the conventional mechanism of glucose. Compound 7 was obtained with an additional $99 \%$ enantiomer and a yield of $47.5 \%$ at the reaction time of 22 hours.

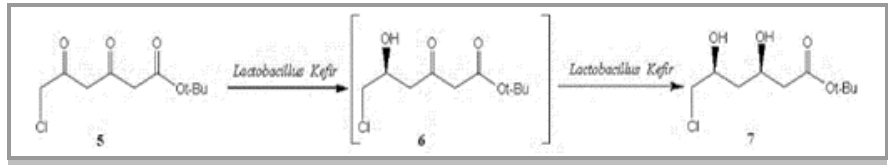

Scheme 17. Use of L.Kefir Biocatalyst Cell in Improving Compound Synthesis [7]

\subsubsection{Aldolase}

The use of 2-deoxy-D-ribose-5-phosphate aldolase is shown in Gijsen and Wong [41] in a one-part reaction for the synthesis of chiral compounds from non- 
circular compounds that are readily available. Intermediate 11 was synthesized in a mixed reaction consisting of $133 \mathrm{mg}$ of chloroacetaldehyde and 264 $\mathrm{mg}$ of acetaldehyde in a total volume of $20 \mathrm{ml}$ reaction. (Scheme 18). Intermediate 12 Atorvastatin can easily be obtained from oxidation 11, although Aldolase exhibits little dependence on Chloroestaldehyde and is rapidly deactivated in a concentration above the required amount of aldehyde and hence a large amount of Aldolase in the reaction is required. Another factor was that, given the nature of the reversibility of the Aldol reaction, a very long reaction time of 6 days made the process more impractical.

Subsequent studies were carried out by Liu [42] and their colleagues; they used modified aldolase, which resulted in an increase in yields of $12 \%$ to $43 \%$ compared to before, $25 \%$ for a wide variety of aldolase, and also the reaction conditions were as before is. the reaction process was considerably improved by

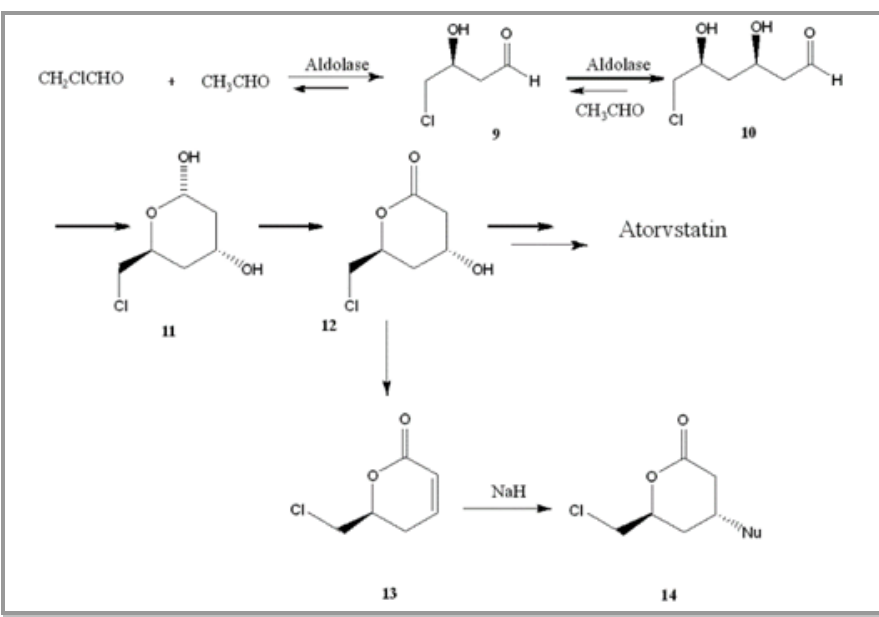

Scheme 18. Application of 2-deoxy-D-ribose 5-phosphate aldolase in the synthesis of chiral compounds and intermediate synthesis [11]

[43] and his colleagues from various companies, which, using the enzyme aldolase and the DNA library review and their resistance to chloroacetaldehyde, resulted in increased efficiency and improved reaction variables. All of these improvements in Synthesis 12 resulted in production at a scale of $100 \mathrm{~g}$ at a total reaction time of 3 hours with $99.9 \%$ ee and a decrease in consumption of 10 times the catalyst. Also, the DSM, also called DSM, is a multinational Dutch company active in the fields of health, nutrition ,and materials.) Pharmaceuticals Company made a synthesis for the combination of 12 catalyzed by Aldolaz at an industrial scale. Jennewein and colleagues reported from the DSM drug company of altypes of improved aldolase using direct evaluation and high efficacy.

Recently, researchers at DSM Corporation reported the conversion of 12 to non-saturated lactone 13; in addition, they were observed by various types of nucleophiles, such as $\mathrm{AcSH}, \mathrm{HCN}, \mathrm{MeNo}_{2}$, etc., a wide range of different pyranoside derivatives of 14, thereby increasing the versatility the process was synthesized in other mediator mediums.

\subsubsection{Nitrilase}

Researchers at Diversa Company [44] created a large genome collection (more than 200) of nitrilases through the extraction of DNA from specimens in different natural habitats and used them in host E. coli, and furthermore, these nitrilases used to catalyze different types of enantioselective reactions. They found from their collection that nitrilase could be desymmetrization from the combination of 15, 3hydroxyglutaronitrile (Scheme 19) to the intermediate of atorvastatin, the combination of 16, (R) -4-cyano-3hydroxybutyric acid. The process was performed on a $1 \mathrm{~g}$ scale at a concentration of $240 \mathrm{mM}$ of compound 15 .

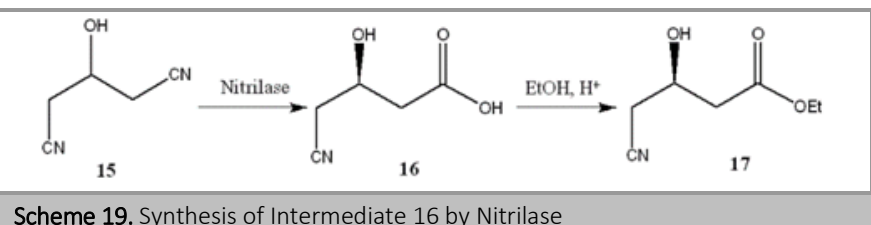

The isolated product of 16 with a yield of $98 \%$ and $95 \%$ ee was obtained at a total reaction time of $22 \mathrm{~h}$. The next sterilized sterilization of the compound 16 is an intermediate of atorvastatin. When the process was carried out, more efforts were made under more practical conditions such as higher concentrations of substrates, such as 2 mole and 3 mole, e.e. values were $89.2 \%$ and $87.6 \%$ respectively [45]. This low enantiopurity does not meet the intermediate requirement for the atorvastatin intermediate. The possible solution is the enhancement of enantioselectivity Nitrilase, a method used by Desantis et al. [45] to achieve this, was a specific evaluation technique that was called mutagenic saturation of the site of the gene [46]. This technique is essentially the replacement of each single amino acids from a protein with any of the other naturally occurring naturally occurring 19 amino acids and expressing this gene in E. coli host organisms. The unchanged nitrilase species is 330 amino acids per long. Thus, in this technique, all modified Nitriles, including more than 30,000 clones and each was screened to identify mutant enzymes with improved enantioselectivity.

The most effective modified nitrilase catalyzed the synthesis of 16 at a concentration of 3 moles and 96\% purity, and $98.5 \%$ ee at a total reaction time of 15 hours. This is a significant improvement both in terms of enantiomer and in terms of reaction time in comparison with the early nitrilases was unchanged. Bergeron et al. [47] of Dow Pharmaceuticals Company used Nitrilaz from Diversa to develop a scalable process of synthesizing 17 low-cost epichlorohydrin 
primary materials; then they found a one-step reaction to synthesize 15 (Scheme 20a) on a factory scale because the exact control of the $\mathrm{pH}$ required to proceed with an efficient reaction is inadequate, so they devised a two-step process for synthesis (Scheme 20).

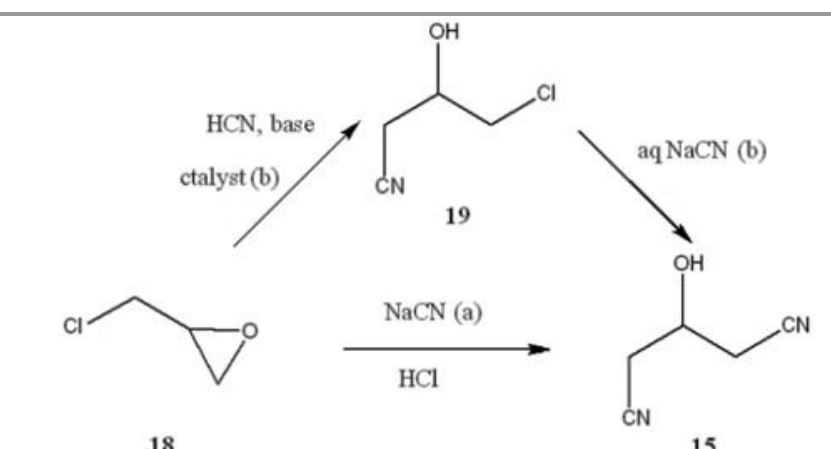

Scheme 20. (a) Synthesis of intermediate 15 in one-step (b). Synthesis of intermediate 15 more efficiently in two steps.

The yield achieved for synthesis is 19, 93\% for synthesis and 15, 68\% for synthesis.The Separation was carried out by extraction with 2-methylpropane-1ol. The stage catalyzed with nitrilase was used to obtain the compound 16, 252.5 g of precursor 15 at a concentration of 3 moles. The product 16 was observed with $98.8 \%$ ee and the overall yield was $81 \%$ at the reaction time of 16 hours. Extracting 16 from the reaction mixture due to its solubility in water and the presence of cell mass in the mixture was difficult to distinguish from the acidification of the medium and filtering using the - Celite filter followed by Descentos et al. Extraction with methyl ethyl ketone is used. This process has a larger scale (more than 200 times) than the previously reported method by Desantis et al. To reduce the catalyst cost, in other words, nitrilase, in a variety of Pseudomonas fluorescence bacteria through the Pfenex expression technology developed by the Dow Chemical Company they said. Nitrilase is found in more than $50 \%$ of total protein in the protein; this high level of expression is directly and easily involved in the downstream industry, resulting in a lower cost.

\subsubsection{Lipase}

Sun et al. [48] performed a combination of 21a on a hot scale with a $98 \%$ ee with a yield of $40 \%$ in a kinetic solution of a20 via a sterie exchange (Scheme 21) using an Argribacter $s p$ lipase enzyme the reaction time was 45 hours. The interstitial atorvastatin a22 was synthesized with $77 \%$ efficacy by chemical methods.

They later reported the synthesis of intermediate atorvastatin, kaneka alcohol 23, using b20 as an enzyme precursor and lipase from Alcaligenes sp.; also, it was observed that with the same reaction time decreased to 30 hours at this stage. Their design is not sufficiently large enough for large-scale synthesis, because not only this kinetic method results in a maximum of $50 \%$ theoretical, but also because of the large number of reaction steps, a large number of intermediates with high reaction time after the enzyme synthesis is b-a21.

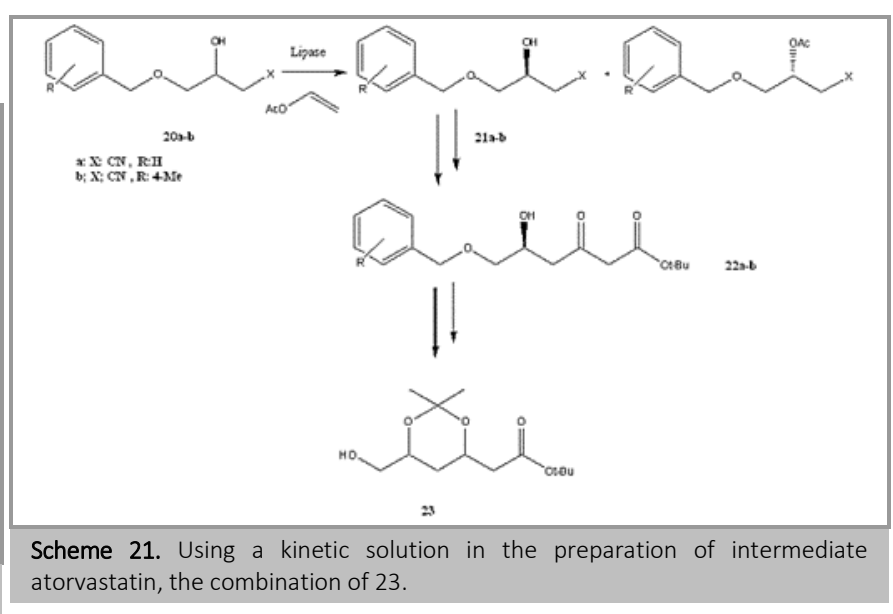

(S) -3-Hydroxy-gamma-butyrolactone, compound 24 is a synthon useful chiral carbonate in carbon 4 and is used as a precursor in the synthesis of food and drugs such as L-carnitine. Wang and Hollingsworth [49] described an easy method for the synthesis of intermediate compounds of atorvastatin 17, of a compound of 24 at a total efficiency of about $80 \%$. (Scheme 22) The compound 24 was synthesized previously with high enantiomeric purity by microbial separation from the 25racemic compound and using cell extraction from recombinant E. coli cells that encodes genes for Enterobacter sp and Rhizobium sp.

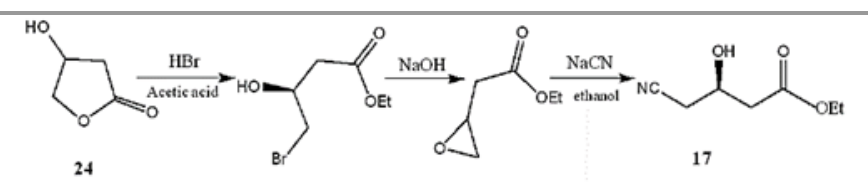

Scheme 22. Synthesis of intermediate compounds of atorvastatin 17

One (S) -4-chloro-3-hydroxybutyrate hydrolyzate was responsible for this reaction, although there was no indication of similarity between the enzyme and lipase or estraz. The hydrolysis lipase catalyst from the racemic compound 25 in the aqueous phase (Scheme 24) can also synthesize compound 24.

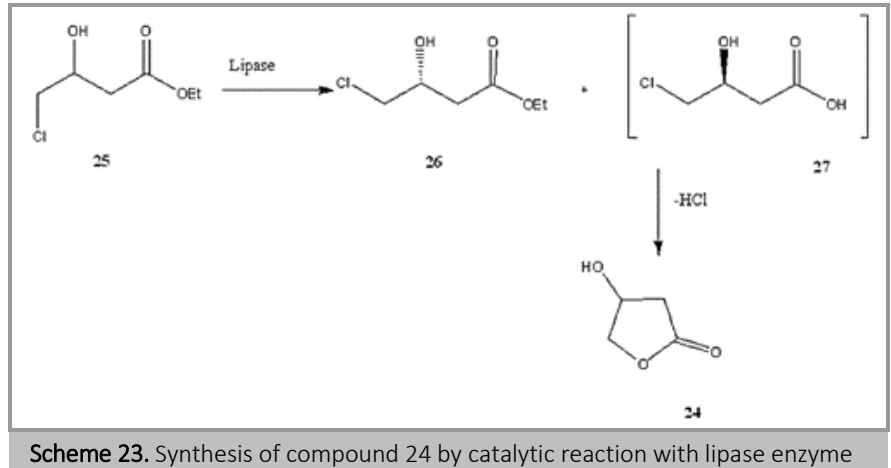

Scheme 23 . Synthesis of compound 24 by catalytic reaction with lipase enzyme

The lipase enzyme spatially hydrolyzes only the enantiomer S, although the resulting acid 27 is unstable 
and easily loses one $\mathrm{HCl}$ molecule to obtain the corresponding lactone 24 with high enantiomeric purity (99\% e.e.); however, when the process is at a yield More than $40 \%$ is in operation, the enantiomeric purity of 24 is diminished.

Lee et al. [50] from the LG chemical company recently reported the synthesis of 24 , which uses three synthesis steps (Scheme 24). The two initial steps of this synthesis were done directly. In the second stage, zinc borohydride was used as a carrier of hydrogen because it was cheaper than other hydrides, such as sodium borohydride. In the third stage, that the lactone ring should not be hydrolyzed under reaction conditions. When the reaction was examined both in acidic conditions and in-game conditions, adverse side effects were observed; therefore, more than 15 lipases, esterase, protease different in terms of their performance in enzymatic hydrolysis.

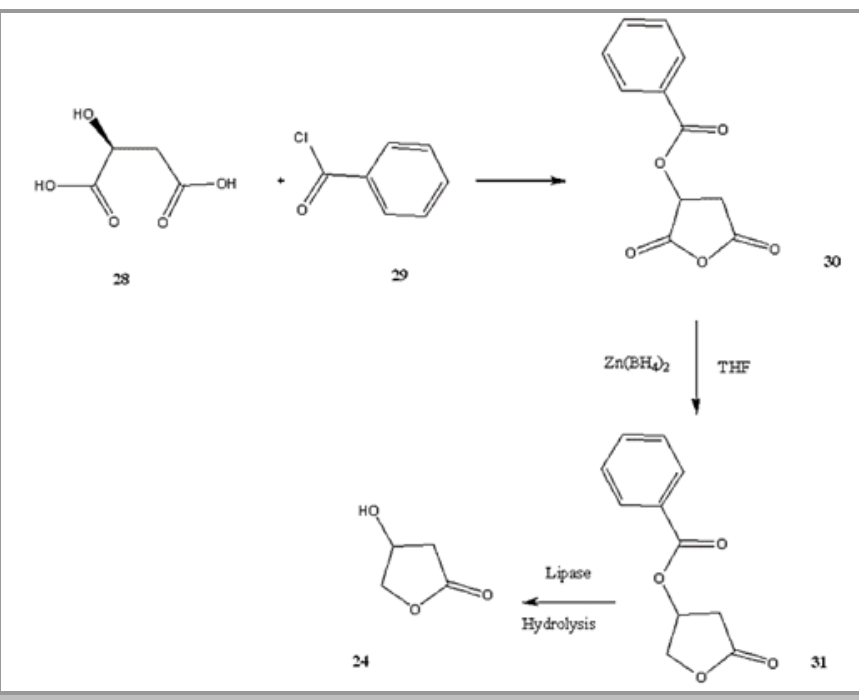

Scheme 24. Enzymatic synthesis of compound 24 in more favorable conditions

The best-observed result was Candida rugosa lipase, which was immobilized on Amberlite XAD-7 polymer as polymer support and then used to hydrolyze the compound 31 to obtain 24 with $99.8 \%$ ee. This enzyme hydrolysis appears to be non-spontaneous. When racemic malic acid was used, the product 24 was also prepared by the racemic; therefore, it was necessary to use a precursor with a chiral L-maleic acid structure for this process. This process was performed on a tone scale and the overall response rate was more than $80 \%$ at a reaction time of 14 hours.

Fishman et al. [39] developed a 2-stage enzyme process for the production of $(\mathrm{R})$-ethyl-3-hydroxybutyrate, a compound of 35 (Scheme 25) and a plurality of kilograms. Both enantiomers 34 and 35 were found to have a $99 \%$ purity and ee of more than $96 \%$ and a total reaction efficiency of $73 \%$. The first reaction involves acetic acidification of the racemic 32 with vinyl acetate to form the compound 34, which was performed by selective acetylation of (R) -22 . In the second phase of the reaction, compound 33 is exposed to ethanol to create a pure optical compound 35, which is alkylated. Immobilized Candida Antarctica Lipase B was used in both stages, high efficiency and high selectivity. The motionless lipase was closed to a column and the reaction was circulated between successive enzymatic beds until the desired conversion was achieved. The desired and desired product was separated after two stages of distillation apart from the reaction mixture.

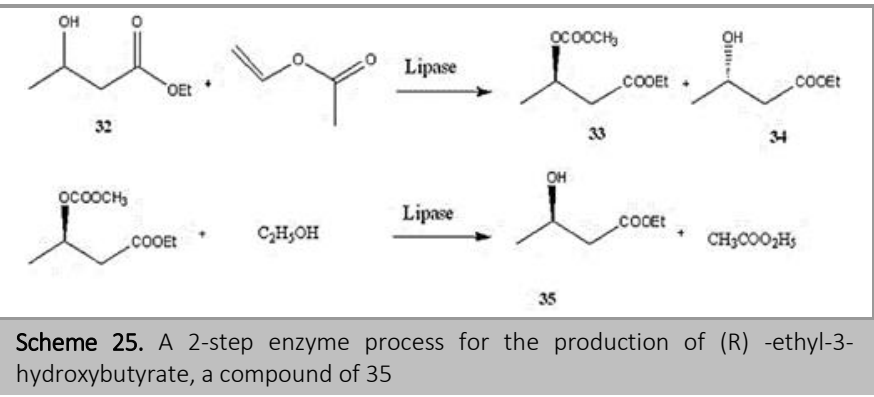

\subsubsection{Ketoreductase and halohydrin dehydrogenase}

Researchers at Bristol-Myers Squibb (BMS) Inc. [39] synthesized $37 \mathrm{a}$, dihydroxy ethyl ester on a hot scale with high ee (more than 97\%) of the corresponding keto ester a-36b, by synthesizing Acinetobacter $s p$ as a whole cell biocatalys. (Scheme 26). Keto-reductase is secreted from these species responsible for this high enantioselective reduction, followed by the tert-butyl ester 37b, the kaneka alcohols 38a and 23 also synthesized.

A complete transformation of the $36 a-b$ substrate to produce the corresponding 37a-b dihydroxy esters was performed at $99.3 \%$ e.e. and $63.3 \%$ d.e. in 24 hours. The crude product was obtained by optical chromatography and crystallization with pure e.e. and 99\% pure. They subsequently encoded the encoding gene of ketoredoktase, and they did this by colonizing

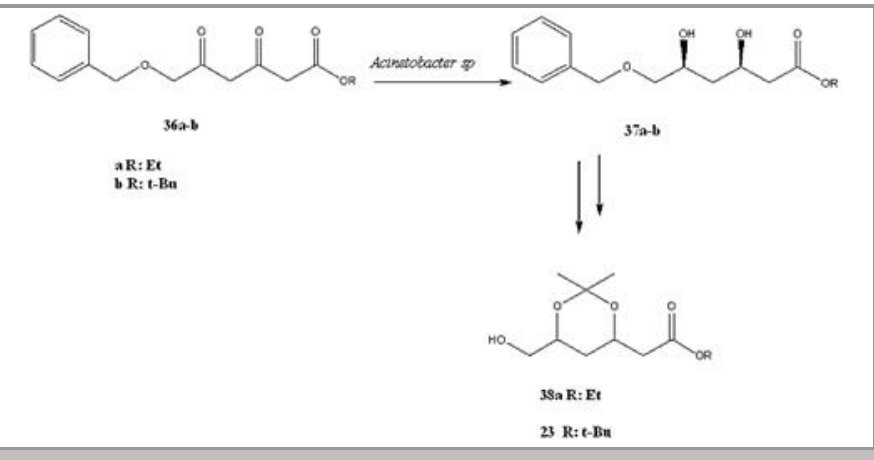

Scheme 26. Synthesis of kaneka 23 and a38 alcohols via the a-b37 intermediate produced by the corresponding ketoester $36 \mathrm{a}-\mathrm{b}$

E.Coli [51]. They then used cell extraction of E. coli recombinant cells to reduce the 36 a space crop. The efficiency was significantly higher than $99.3 \%$ for $37 \mathrm{a}$ with e.e. greater than $99.9 \%$ and $99.8 \%$ for a reaction time of 3 hours.

Elenker et al. [52] tried to synthesize the atorvastatin(R) 41 intermediate through sequential kinetic 
solutions of the racemic mixture 39 and using halohydrin dehydrogenase (Scheme 27).

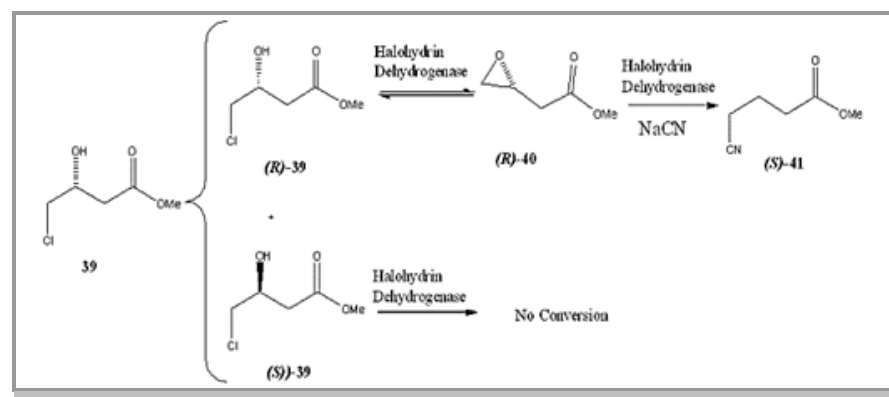

Scheme 27. A kinetic solution for the preparation of atorvastatin intermediates from the mixture of racemic mixture 39 using halohydrin dehydrogenase

Conversion- (S) 39 to intermediate - (R) 41 atorvastatin was not observed; however, the conversion of the enantiomer $\mathrm{R}$ from the compound of 39 quickly results in an intermediate (S) 41. Therefore, the compounds (S) 39 and (S) 41 with e.e. separated more than $95 \%$ by column chromatography from the reaction mixture. Researchers at codexis Company presented a two-step process for the synthesis of 17 atorvastatin. Full conversion of the substrate 25 occurred in the first step of the catalyst process by ceturtodecotase (Scheme 28).

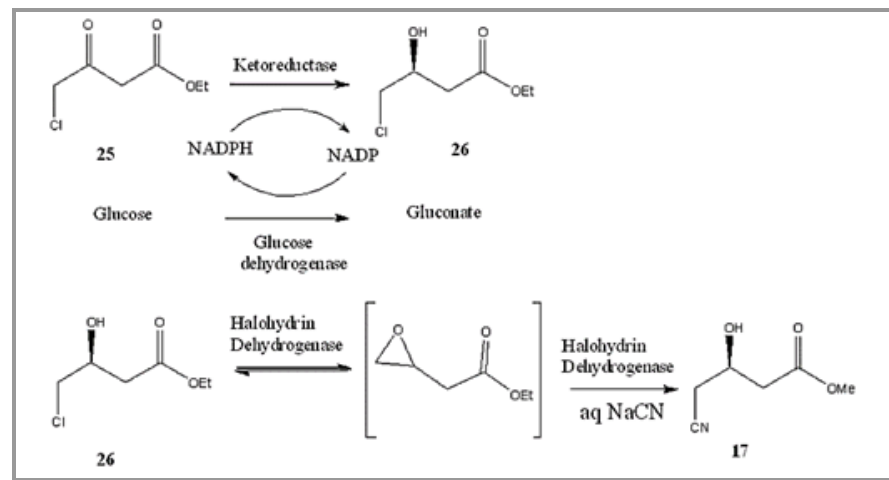

Scheme 28. Intermediate synthesis 17 in a two-step process with high chemical purity

The reaction mixture was extracted with ethyl acetate at this step, then washed with sodium bicarbonate sulfate, and then separated. Finally evaporated under reduced pressure and the product 17 was obtained with high chemical purity. The regeneration of the cofactor $\mathrm{NADP}(\mathrm{H})$ involves the conversion of glucose to gluconate catalyzed by glucose dehydrogenase. In the second step, the halohydrin dehydrogenase catalyzed the complete conversion of the 26 to the cyanogen derivatives of the compound 17 through the formation of an intermediate epoxide, with high enantiopurity (greater than 95.95\%). Separation of product 17 includes solvent extraction by filtration and evaporation. The main advantage of this process is the easy separation of the product without the need for distillation except for All enzymes used in this process were synthesized by fermentation of $E$. coli recombinant cells and the encoded genes of coturdoxacate and halohydrin dehydrogenase were derived from Candida magnolia and Agrobacterium radiobacter respectively, and for the glucose dehydrogenase of the two bacteria Bacillus megatrium and Bacillus subtilis that were cloned separately in E.coli cells. The halohydrin dehydrogenase was developed for this process by applying a direct evaluation approach to the production of enzymes that meet the design criteria of the predetermined process. This work is underway with direct-evaluation recombination along with a strategy for statistical analysis of the relationship between proteins sequencing activity. This combination facilitates the optimization of the mutated enzyme. The evolved evolutionary halohydrin dehalogenase, in the process of combining on a catalytic basis, improves the volumetric efficiency of the cyanide reaction by approximately 4,000-fold. Recently, Lonza Inc. has made a good chemical contract for Pfizer, which will carry out this process on an industrial scale. Also won the 2006 Presidential Green Chemistry Competition Award from the United States

Environmental Protection Agency (USEPA) for a "Greener Reaction Conditions" for the development of the process. The biocatalyst's ability to convert chiral compounds to high-value chiral mediators maintains interest in research in this field. Apart from the onset of atorvastatin, many other drug intermediates on the downside of large-scale production use biocatalyst. In this regard, biocatalysts are an important method for producing pharmaceutical intermediates. In general, the main competition for biocatalysts is the relatively low volumetric activity of catalyzed enzymes that results in higher costs for downstream industries as well as difficulty in speeding up. Although advances in evolved techniques such as saturated site mutagenesis, high-performance testing techniques, and ... increased efficiency also led to an exponential increase in response time, and with each increase in the number of enzymes In commercial markets, the acceptance of biocatalyst reactions in the future should be increased [53].

\section{2 combined studies of synthetic materials on statins (synthesis without cyanide)}

The next topic is the short synthesis of cyanide atorvastatin calcium with enantioselective aldol strategy [54]. Short-lived and non-cyanide synthesis of atorvastatin calcium from a 1, 4 diketone substitute, which is highly commercially available, has started at a total reaction efficiency of $40 \%$. A key step in this approach is the asymmetric aldol reaction of an aldehyde with di-ketone in the presence of a combination of open-circuit chemistry $\mathrm{Ti}$ (o-i-pr) $)_{4}$ to create atorvastatin calcium with spatial chemistry (R5). Since its introduction in 1997 by Pfizer, it has been one of the best selling drugs for treating cholesterol, leading 
to long-term safety and long-term benefits [55]. Significant efforts have been made today to search for an asymmetric, efficient and economical approach to combining 42 and have led to the development of a large number of synthetic strategies, including syntheses with chiral [56], chiral auxiliary, catalysts Asymmetric and enzymatic chemistry processes. The well-known strategy of Paal-knorr for the synthesis of Pyrrole, which is derived from two important structural blocks, namely substituted diketone 43 and a side-chain amine, with 7 carbon (combining 44), with a single syn 1 and 3 diol of (S) epocholorohydrin as a chiral material is a reliable process for the asymmetric synthesis of 42 compounds in the industrial scale (Figure 7).

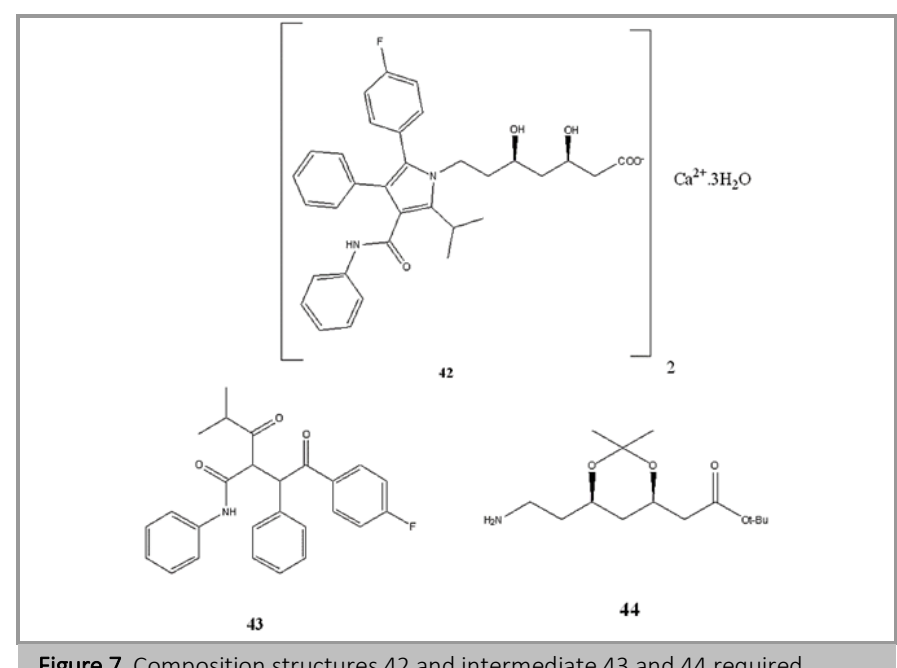

Figure 7. Composition structures 42 and intermediate 43 and 44 required

However, several problems with these side chains 44 such as multi-stage and longterm sequential preparation, as well as the use of high and high amounts of high toxicity cyanide, were coupled Asymmetric Aldol reaction is a simple method with atomic economics for the production of 5-hydroxy-3-oxoesters [57], an important building block for the synthesis enantioselective of statin. This led us to provide a noncyanide and short enantioselective synthesis for combining 42 with a new intermediate 50 by employing an open shiff $\mathrm{Ti}(\mathrm{o}-\mathrm{i}-\mathrm{Pr})_{4}$ that improves the asymmetric aldehyde reaction of aldehyde 49 with diketone [58]. This section reports the results for this topic.

\subsubsection{Study and discussion data}

The retrosynthetic analysis of Compound 42 in Scheme 29 was depicted and the selective reduction of the syn was predicted for the key intermediate 50. Optically active 5-hydroxy-3-oxoesters, 50, can be obtained from a 49-membered asymmetric aldol reaction. Alternate composition Pyrrole aldehyde 49 can be obtained from the sum of the two combinations of ketone 43 and the 3-carbon amino diethyl acetal 47 compounds during the well-known Paal-knorr synthesis for Pyrrole. We showed the asymmetric synthesis 42 in Scheme 30; the compound 47 was provided with a side chain in carbon 44 of commercially available acrolein, the method presented in the slightly improved article with a total yield of $62 \%$.

With the increase of Michael, acroleinium and sodium nitrate in $\mathrm{HOAc} / \mathrm{THF} / \mathrm{H} 2 \mathrm{O}$ at $0{ }^{\circ} \mathrm{C}$, the nitroaldehyde 45 was obtained at $98 \%$ yield, which was combined with triethyl orthoformide in the presence of $\mathrm{p}-\mathrm{TsOH}$ in $\mathrm{EtOH}$ at room temperature and a total yield of $71 \%$ it is protected as triethyl acetal.

The hydrogenation of the compound 46 was subjected to the atmospheric pressure of 10 atmospheres from $\mathrm{H}_{2}$ on $\mathrm{Pd} / \mathrm{C}$ at room temperature for $12 \mathrm{~h}$, and the amino de ethyl acetal composition was obtained at a low yield. Pyrrole 48 in $83 \%$

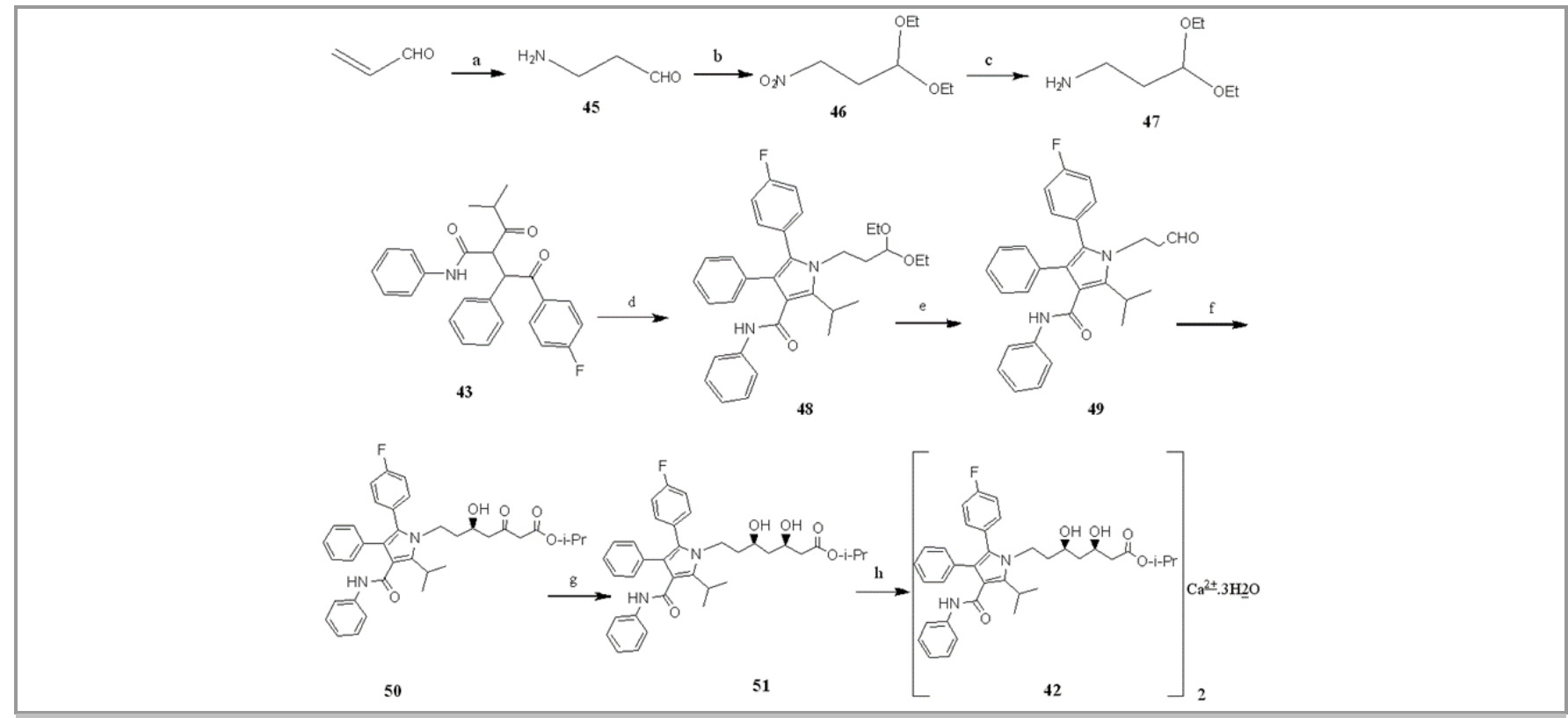




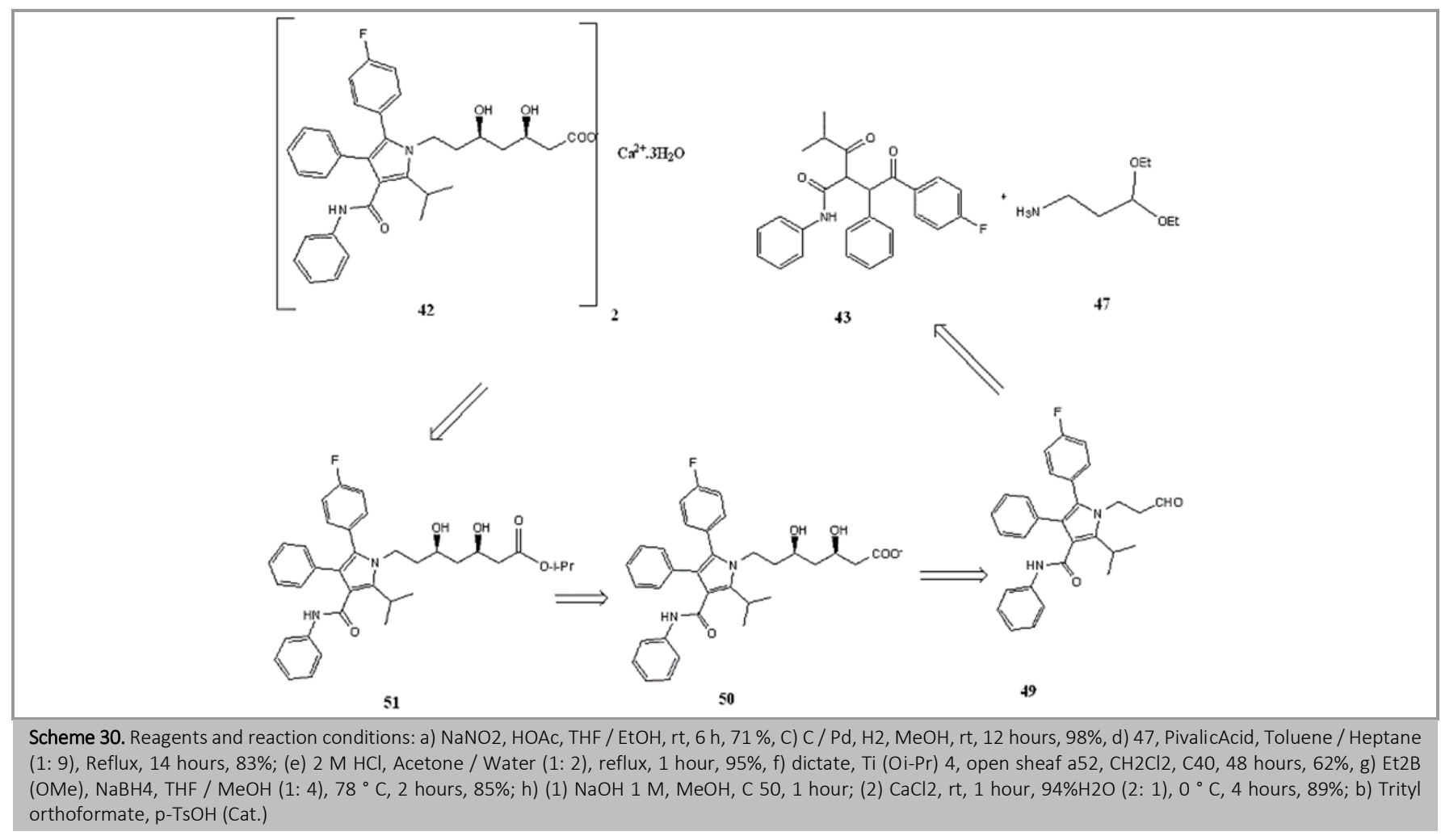

Efficiency [54]. Paal-knorr condensation of diketone 43 and 47 was carried out in refluxing toluene /heptane $(1: 9 \mathrm{v} / \mathrm{v})$, by azeotropic removal of water in presence of pyvalic acid to give pyrrole $48 \%$ in $83 \%$ yield. The deprotection of 48 by Dilute $\mathrm{HCl}$ in water /acetone (1:1 volume ratio) gave the desired aldehyde 49 at $95 \%$ yield. With the available aldehyde 49 , we were in the position of making the compound 42 with 5Rstereochemistry by an asymmetric addition of diketone to 49 in the complex of the $\operatorname{Ti}(\mathrm{O}-\mathrm{i}-\mathrm{Pr})-$ Schiff base complex [54].

To evaluate the ligands, the initial test was performed and from leq enhancer, which simultaneously produced several open shif ligand of chiral g-a52 (Figure 8) and $\mathrm{Ti}(\mathrm{O}-\mathrm{i}-\mathrm{Pr}) 4$ in $\mathrm{CH}_{2} \mathrm{Cl}_{2}$ at $40{ }^{\circ} \mathrm{C} 48$ hours (Table 1, Entry 7).

As shown in Table 1, it was found that the combination of 52a is the most suitable ligand for the reaction of $\gamma$ aldol-enantioselective. (Table 1, input 1, efficiency $62 \%$, e.e. $82 \%$ ).

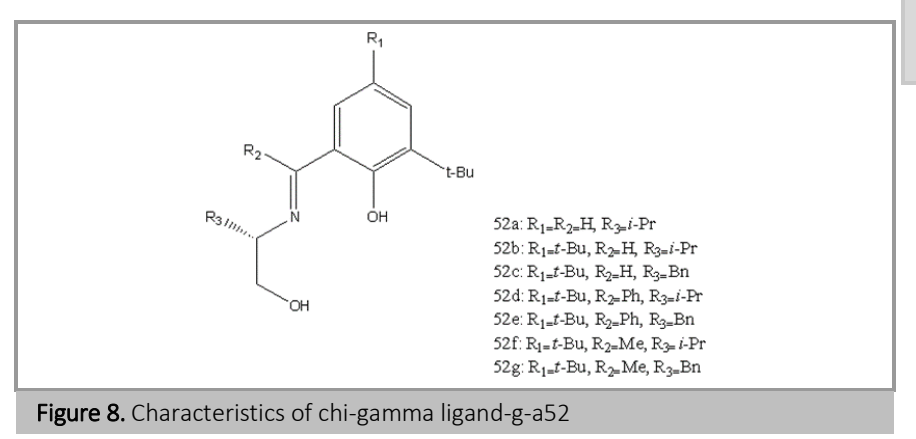

Table 1. Effect of Ti (O-i-Pr) $)_{4}$, the schiff base g-a52 in enantioselective with increasing diketone to aldehyde 49

\begin{tabular}{|c|c|c|c|}
\hline Entry & Schiff base & Yield ${ }^{b}(\%)$ & eé(\%) \\
\hline 1 & $52 a$ & 62 & 82 \\
\hline 2 & $52 \mathrm{~b}$ & 55 & 71 \\
\hline 3 & $52 \mathrm{c}$ & 57 & 31 \\
\hline 4 & $52 d$ & 60 & 71 \\
\hline 5 & $52 \mathrm{e}$ & 61 & 20 \\
\hline 6 & $52 \mathrm{f}$ & 55 & 79 \\
\hline 7 & $52 \mathrm{~g}$ & 58 & 61 \\
\hline
\end{tabular}
demonstration, we did react to our catalytic efficiency in different amounts of a11 in a wide temperature range. As shown in Table 2, the temperature drop is one Enantioselective with a decrease in chemical efficiency even after a long time resulted in the reaction. According to the table, it was found that the temperature of $-40^{\circ} \mathrm{C}$ is the optimum temperature for this reaction, which produces Aldol 50 at $62 \%$ yield and $82 \%$ e.e.

Table 2. The effect of reaction conditions on enantioselective with increasing diketone to aldehyde 49

\begin{tabular}{llllll} 
Entry & $\begin{array}{l}\text { Ligand } \\
\text { (mol) }\end{array}$ & Temp(0c) & Time(h) & Yield(\%) & eè(\%) \\
\hline 1 & 100 & 62 & 82 & & \\
2 & 100 & 55 & 71 & & \\
3 & 100 & 57 & 31 & & \\
4 & 100 & 60 & 71 & & \\
5 & 50 & 61 & 20 & & \\
6 & 10 & 58 & 61 & & \\
\hline
\end{tabular}


Reducing the amount of schiff base also reduces enantioselective and reduces chemical efficiency; therefore, the molar amount of Schiff base was needed to obtain satisfactory results. Selective reduction syn of 50 Narasaka using Etras (Et2B (OMe) / NaBH4, THF / $\mathrm{MeOH}(4: 1), 78^{\circ} \mathrm{C}$ ), used diol 51 in a yield of $58 \%$ in favor of isomeric syn (99: 1 anti,syn) [59] of nanoscale by crystal was increased by up to $99 \%$. The syn conformation by the NOESY NMR spectroscopy of the Ketal 53 obtained from the composition of 51 by the effect of 2 and 2-dimethoxy propen in the presence of some The PPTS catalyst was confirmed. This study clearly demonstrated a strong interaction of NOE between carbon hydrogen $3(\delta=1.39 \mathrm{ppm})$ and carbon $1(\delta=3.70-3.74 \mathrm{ppm})$ and carbon $2(\delta=4.19-4.25 \mathrm{ppm})$; However, the interaction between carbon hydrogen 4 $(\delta=1 / 32 \mathrm{ppm})$ and carbon 1 or carbon 2 is not seen, thus indicating the syn comfort for carbon 1 and carbon 2hydrogen. (Figure 9).

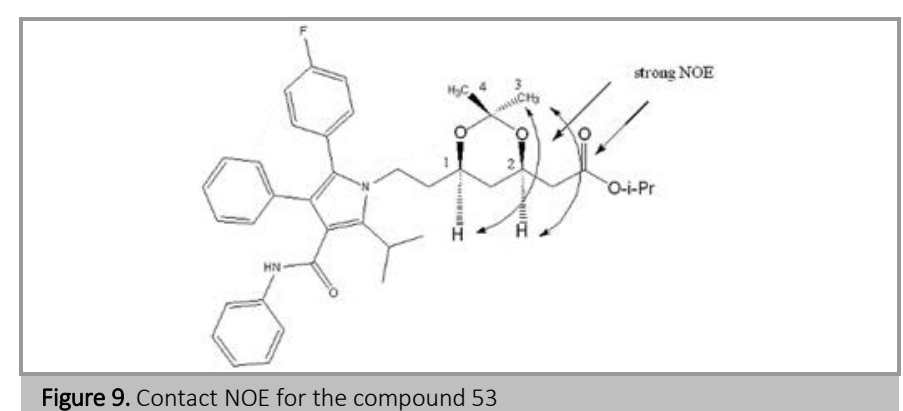

The saponification of isopropyl ester 51 with $1 \mathrm{M}$ aq $\mathrm{NaOH}$ and subsequently calcium salt formation after $\mathrm{CaCl}_{2}-2 \mathrm{H}_{2} \mathrm{O}$, calcuim atorvastatin 42 is provided. The enantiomeric purity of 42 was determined by HPLC chiral according to the European Pharmacopoeia, more than $99 \%$ e.e. As a result, a new asymmetric and 5-step synthesis of atorvastatin calcium 42 was performed at a total efficiency of $40 \%$, consisting of a di ketone 43 and a $\mathrm{Ti}$ (O-i-Pr) ${ }_{4}$ Schiff base complex, which improves the asymmetric aldol reaction as a key step the reaction was used. This approach is shorter for compounding 42 compared to other reported methods.

\section{Comparison of atorvastatin in performance improvement versus other statins}

\subsection{Clinical examination of the superiority of atorvastatin versus medium-grade statins}

At first, a general review of the clinical profile of atorvastatin (lipitor) was performed compared to other statins including fluvastatin, lovastatin, pravastatin and simvastatin. The method used was to collect data from 21 clinical trials of 2502 patients and 23 patients per 1769 of the atorvastatin studies in the United States and international and academic research centers. In these cases, patients with fat dysfunction received atorvastatin in doses of 10 to 80 milligrams. Most patients had moderate to severe hypercholesterolemia and were treated for 4 to 24 weeks [60].

Decrease dependency Dosages at LDL cholesterol levels for atorvastatin have been reported in the range of $41 \%$ to $61 \%$ for dosages ranging from 10 to $80 \mathrm{mg}$. Additionally, serum triglyceride levels in hypercholesterolemia patients have decreased by up to $43 \%$. Generally, statins have consistent and acceptable characteristics, which indicate a widespread presence in the present compounds in the market, including lovastatin, pravastatin, simvastatin and fluvostatin [61]. Data from individual studies in patients with hyperlipidemia from different phenotypes show that atorvastatin is lower in LDL cholesterol than in other statins. While maintaining its safety profile at a level comparable to those sold in the market. The present analysis combines the safety data collected from 21 completed studies to evaluate the clinical safety of atorvastatin in a database. The 23 ongoing trials provided additional information on increased levels of transaminase and phosphokinase. To determine whether increasing the efficacy of atorvastatin is associated with increased side effects compared with other drugs at this level, we compared this relationship between treatment, dosing, and the duration of treatment. Most of the patients in these tests have moderate to severe hypercholesterolemia, and samples of patients may be treated with cholesterol-lowering drugs. Among of the 2505 patients, almost all of them received a dose of atorvastatin, and 1721 patients (69\%) were treated for at least 6 months and 1253 (50\%) were treated for at least 12 months. Although most studies have been conducted to determine the dose level to achieve the national assessment goals at the correct level of cholesterol, more than two-thirds of all patients were adequately treated with an initial dose of $10 \mathrm{mg} /$ day (Approximately 1083 patients). As a result, more safety information is available from patients receiving a dose of $10 \mathrm{mg}$ per day. The focus of this study is the comparison of atorvastatin with other statins (simvastatin, lovastatin, and pravastatin) in clinical trials (about 601 patients treated), such as cholestypole and fenofibrate. When we performed the patients in a trial, of 4271 atorvastatin recipients, more than 900 patients were treated with at least 24 months of gestosis.

The results of the patients treated are summarized in Figure 10. For doses of 10 to $80 \mathrm{mg}$ Patients treated for 1 year (with all of the safety parameters examined at the end of the year) were then treated in a 1-year supplemental study (with safety parameters analyzed at the end of the second year). Atorvastatin safety profile was similar in the first and second years, and was similar to those of lovastatin (Table 3). The side effects of the atorvastatin therapy over the two years was similar to those of lovastatin (Table 4). 


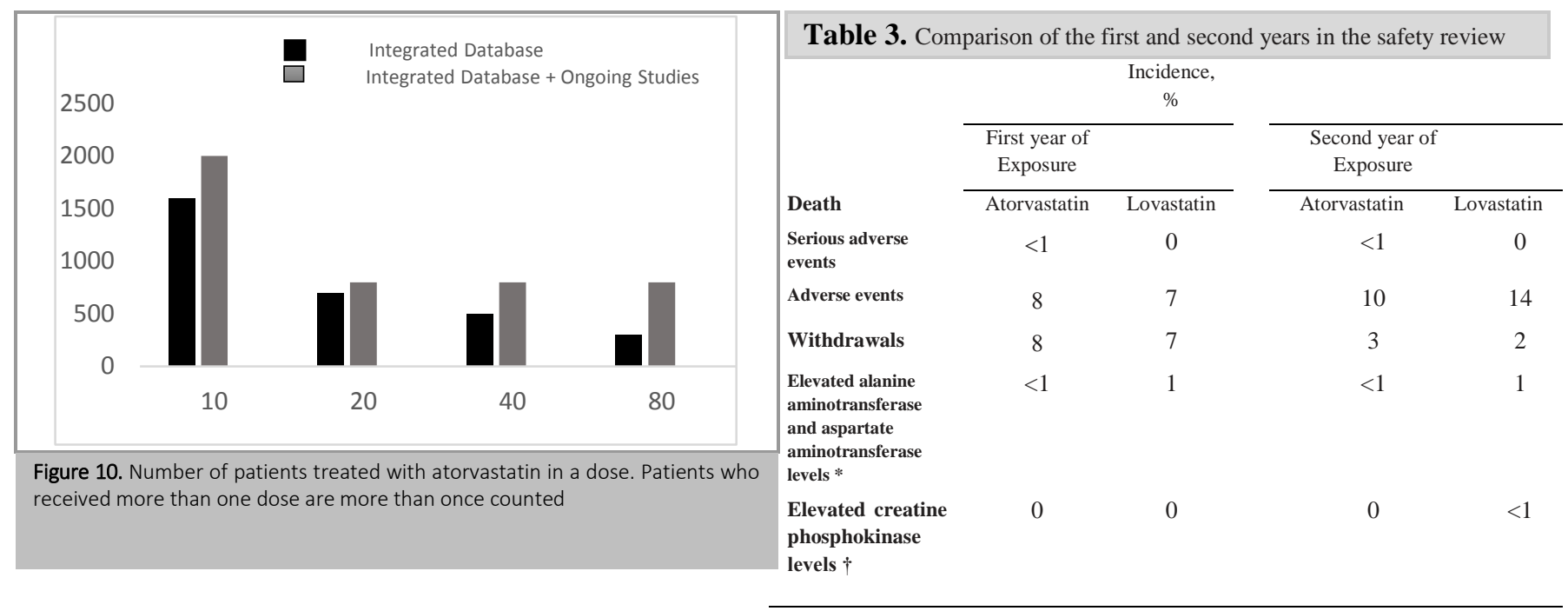

Table 4. Complications of statins in $2 \%$ or more of patients.

\section{No. (\%) of Patients}

\begin{tabular}{|c|c|c|c|c|}
\hline & \multicolumn{2}{|c|}{ First Year of Exposure } & \multicolumn{2}{|c|}{ Second Year of Exposure } \\
\hline & $\begin{array}{c}\text { Atorvastatin } \\
(\mathrm{n}=719)\end{array}$ & $\begin{array}{c}\text { Lovastatin } \\
(\mathrm{n}=193)\end{array}$ & $\begin{array}{l}\text { Atorvastatin } \\
(\mathrm{n}=623)\end{array}$ & $\begin{array}{c}\text { Lovastatin } \\
(n=164)\end{array}$ \\
\hline Digestive system & $62 \dagger(9)$ & $18(9)$ & $34(5)$ & $11(7)$ \\
\hline Dyspepsia & $17(2)$ & $2(1)$ & $5(1)$ & $2(1)$ \\
\hline Flatulence & $18(3)$ & $5(3)$ & $9(1)$ & $4(2)$ \\
\hline Constipation & $16(2)$ & $3(2)$ & $14(2)$ & $2(1)$ \\
\hline Body as a whole & $37 \dagger(5)$ & $14 \dagger(7)$ & $9(1)$ & $7(4)$ \\
\hline Pain & $13(2)$ & $3(2)$ & $3(<1)$ & $3(2)$ \\
\hline Nervous system & $22(3)$ & $6 \dagger(3)$ & $12(2)$ & $3(2)$ \\
\hline Musculoskeletal system & $21(3)$ & $8(4)$ & $12(2)$ & $6(4)$ \\
\hline Myalgia & $14(2)$ & $4(2)$ & $7(1)$ & $4(2)$ \\
\hline Skin and appendages & $19 \dagger(3)$ & $6(3)$ & $12(2)$ & $\mathbf{0}(\mathbf{0})$ \\
\hline Any event & $139(19)$ & $40(21)$ & $76(12)$ & $24(15)$ \\
\hline
\end{tabular}

In these studies, approximately $5 \%$ of atorvastatintreated patients and about $7 \%$ of patients treated with other statins have been seriously ill (leading to hospital, cancer, at a higher death rate). Although the incidence of sustained increase of more than 3 times the normal upper limit may be due to dose dependence, the incidence of doses of 10 to $40 \mathrm{mg}$ per day reduced the level of LDL cholesterol by $41 \%$ to $55 \%$; similar to that observed with Placebo is seen. (Table 5) As patients started taking low or high doses of atorvastatin, the increase occurred more than 16 weeks after the start of treatment with atorvastatin. Only about $3 \%$ of people experienced primary and minor transaminases with a sustained increase of 3 times the normal range. Also, in a long-term study with atorvastatin, in which all 
patients were treated for a similar period, there was no increase in dosage in stable growth.

Table 5. Significant increase in transaminase with atorvastatin dose

\begin{tabular}{ccc} 
& $\begin{array}{l}\text { No. of Patients } \\
\text { Treated }\end{array}$ & $\begin{array}{l}\text { No. (\%) of Patients } \\
\text { With Elevations }\end{array}$ \\
\hline Placebo & 270 & $1(0.4)$ \\
$\begin{array}{c}\text { Atorvastatin by } \\
\text { dosage, mg/d }\end{array}$ & & \\
10 & 1843 & $3(0.2)$ \\
20 & 892 & $2(0.2)$ \\
40 & 811 & $5(0.6)$ \\
80 & 888 & $20(2.3)$ \\
Total & $4271 \uparrow$ & $30(0.7)$ \\
\hline
\end{tabular}

Toxicological studies with atorvastatin have not described new findings and their results are consistent with other statins. The possible mechanism of atorvastatin with a higher efficacy on a high-quality liver effect is through the long-term inhibition of the half-life of 3-hydroxy-3-methylglutaryl coenzyme reductase. Therefore, we performed safety checks on the liver on its dose. An increased incidence of transaminases was more than 3 times higher than normal values for atorvastatin through a total dose range of $0.7 \%$. While direct measurements are not possible in many patients compared to other statins, this is similar to those reported for other drugs in this group: $1 \%$ for simvastatin, $1.1 \%$ for fluvastatin, $0.9 \%$ for lovastatin, and $1.3 \%$ for pravastatin. Also, the incidence rate of Atorvastatin is $2.3 \%$ for $80 \mathrm{mg} /$ day compared with lovastatin $80 \mathrm{mg} /$ day (1.9\%). Comparing fat loss and changes in liver test results Compared with atorvastatin with other statins, this drug shows a lower reduction in LDL cholesterol levels. For example, a $40 \%$ decrease in LDL cholesterol by lovastatin was associated with elevated levels of alanine aminotransferase in $1.9 \%$ of patients; while a $40 \%$ decrease in LDL cholesterol by atorvastatin was observed with an increase in the level of alanine transferase amino acids in $0.2 \%$ of patients. Although LDL cholesterol is lower than $2.58 \mathrm{mmol} / \mathrm{L}$ in patients with coronary artery disease, the concern is whether the level of cholesterol can be greatly reduced. In 20 patients with $\mathrm{LDL}$ cholesterol less than $1.29 \mathrm{mmol} / \mathrm{L}$ for 24 months, no difference was observed between the patients and the control subjects in adverse events. Statins have a consistent and acceptable immunity profile and are proven due to the widespread presence of these compounds present in the current market such as lovastatin, fluvastatin, pravastatin, and simvastatin. Atorvastatin has a superior effect on reduced-fat in a given dose; the results from 44 studies indicate that atorvastatin has a safety profile in comparison to other statins in this category. Due to its superior properties and its greater efficacy and equivalent safety, atorvastatin has the highest risk-of-interest ratio among statins.

\section{2 Newer generation of statin and its superiority in terms of efficacy with atorvastatin}

This section will examine the effects of fat modification by two new statins, rosuvastatin , and pitavastatin in comparison with other statins, especially atorvastatin. rosavastatin shows an improvement in the pharmaceutical and clinical properties of other existing agents. The massive reduction observed in low-density lipoprotein with rosuvastatin, even at the onset of a dose of $10 \mathrm{mg}$, and patients who replaced other statins with $10 \mathrm{mg}$ of rosuvastatin, should improve the achievement of goals while decreasing the need for stabilization. The ability of rosuvastatin to improve other elements of the fatty state, such as high-density lipoprotein (HDL-C), triglycerides and non-HDL-C fats, may help patients with diabetes and metabolic syndrome. Increasing HDL-C combined with more efficacy of rosuvastatin to reduce LDL-C and nonHDL-C fats, may require the need for combined therapy [62]. The results of several studies about rosuvastatin for the next 5 years expect this medicine to help with the underlying evidence for statin therapy and prevention of cardiovascular disease.

\subsubsection{Medical need}

Recent evidence suggests that further reductions in LDL-C are associated with further improvement in cardiovascular disease and mortality. The study of the evaluation and treatment of thrombolysis by the administration of Pravastatin or Atrovastatin Evaluation and Infraction Therapy-Thrombolysis in Myocardial Infraction 22(PROVE-IT) compares the effect of severity against the mean reduction of LDL-C in counteracting cardiovascular events in patients with the acute coronary syndrome. 4162 patients hospitalized for acute coronary syndrome during the past 10 days were randomized to receive $40 \mathrm{mg}$ pravastatin (in moderate therapy) or $80 \mathrm{mg}$ atorvastatin (in severe treatment) with an average follow-up of 24 months. The $80 \mathrm{mg}$ atorvastatin significantly reduced LDL-C compared to pravastatin $40 \mathrm{mg}$. In addition, atorvastatin reduced the risk of death or major cardiovascular events by $16 \%$ compared with pravastatin $(0.005 \%)$, compared with $0.45 \mathrm{mg} / \mathrm{ml}=\mathrm{P}$ ) The results of the PROVE-IT study, along with other findings from tests specifically performed on statins, show a clear correlation between LDL-C levels and cardiovascular events. (Figure 11). 


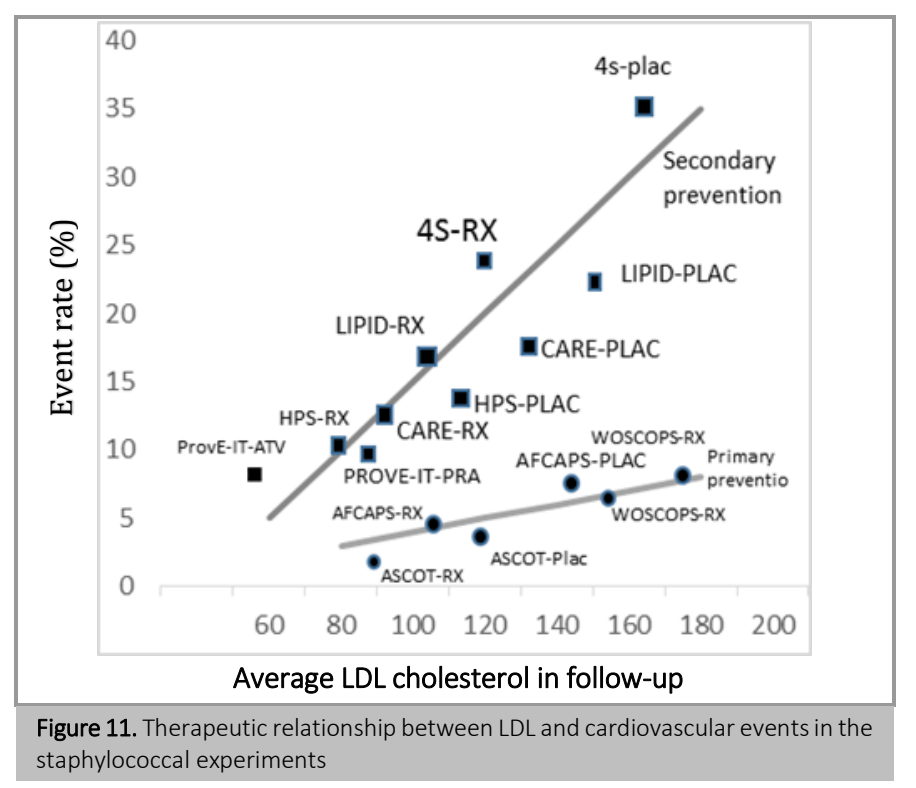

The results of reverse Atherosclerosis experiments and the reduction of fast fats provided more evidence for the beneficial effects of severe fat reduction [63]. The REVERSAL (Reversing Atherosclerosis with Aggressive Lipid Lowering) study of ultrasound waves in the arteries has been used to assess the progression of atherosclerosis in patients with cardiovascular disease (CHD) and has been treated with pravastatin 40 $\mathrm{mg}$ or atorvastatin $80 \mathrm{mg}$ for 18 months. Of course, atorvastatin significantly prevented the progression of coronary artery atherosclerosis compared to pravastatin $(\mathrm{P}=0.002)$. The primary levels of LDL-C in the atorvastatin group $(2.5 \mathrm{~mol} / \mathrm{L})$ were $46 \%$, compared to $25 \%$ in the group of pravastatin $(2.85 \mathrm{mmol} / \mathrm{L})$ decreased $(\mathrm{P}=0.0001)$. The results of PROVE-IT and REVERSAL indicate the benefits of severe fats reduction.

Evidence suggests that decreasing LDL-C levels below current levels may be associated with a reduction in coronary improvement along with clinical improvement. Also, findings from cardiac studies and the joint study of atorvastatin and diabetes indicate that patients with a lower level than the present LDL-C level can benefit significantly from statin therapy. Recent changes in the national education program for cholesterol in adults show that LDL-C is lower than 1.8 $\mathrm{mg} / \mathrm{L}$ for high-risk patients, especially in patients with several major risk factors that are at high risk they can be useful. As recent studies have shown beneficial effects in reducing LDL-C levels. Also, the treatment guide has lowered the recommended lipid goals, with more patients now eligible for statin therapy. There are also updated guidelines for specific groups of patients identified as those at increased risk, including those with type 2 diabetes and metabolic syndrome. Using 2001NCEP ATP III guidelines to US population data from the third National Health and Nutrition Survey shows that 21 million people are eligible for treatment.
Achieving cholesterol goals are linked to a reduction in the mortality rate due to cardiovascular disease. In the Greek study of atorvastatin in coronary heart disease, GREACE, a relative reduction of $43 \%$ in all deaths in patients with statin dosage stabilized, in order to achieve European goals in 1998 (less than $3 \mathrm{mmol} / \mathrm{L}$ ), in Compared to those who have had routine care (including changes in lifestyle, in addition to fat loss treatment, if necessary). Several surveys have shown that many recipients of lipid-lowering drugs are not able to achieve the goals of the past, and there is a considerable concern that there are goals that are no more accurate for lowering LDL-C. There are several reasons for the inability to achieve lipid goals, including the use of less effective factors and the inability to stabilize high-dose fat loss treatment. As the population of people eligible for statin therapy is expanded, more stringent treatment strategies are needed to meet more stringent and more precise goals. Particularly, statins that are more effective in lowering LDL-C in initial doses are needed to reduce the need for dose stabilization. Also, more and more fat and nonlipid parameters are involved in CVD, and in those that can improve these risk factors, there may be a greater reduction in CVD.

\subsubsection{Therapeutic class review}

Currently, a wide range of statins including the first available statin, lovastatin and semi-synthetic compound, simvastatin , and pravastatin are available for clinical use. The development of the statutory pharmaceutical classification continued with the introduction of a fully synthesized blend of fluvastatin (racemic mixture) in 1994. The pure synthetic light stati cerivastatin, was launched in 1997, but due to its high prevalence, rhabdomyolysis was taken from the market. Atorvastatin (a pure enantiomer) was also marketed in 1997 and more effective than existing statins.

Further development of statin drugs continued, and the next generation of statins, was launched in 2003 in several countries around the world. In the same year, pitavastatin was distributed to people in Japan. There is currently limited information on the efficacy of pitavastatin to reduce LDL-C levels, and most of the findings are published in Japanese patients.

\subsubsection{Clinical Performance of New Statins}

\subsubsection{Reduction of low-density lipoprotein cholesterol}

The efficacy of rosuvastine was studied in a comparative study and controlled trials in patients with hypocholesterolemia and several other patients. In patients with hypocholesterolemia, the analysis of collected data from three 12-weekly comparative 
studies of rosuvastatin and atorvastatin showed that rosuvastatin $10 \mathrm{mg}$ significantly reduced LDL-C compared to atorvastatin $10 \mathrm{mg}$ [64]. [(P<0.001) (Table 6)].

Rosavastatin was also compared in a 52-week study with atorvastatin; patients (412) received fixed doses of rosuvastatin or atorvastatin for the first 12 weeks of treatment, and then doses subsequently doubled in 8 weeks, for patients who failed to achieve the NCEP ATP III goals. In 12 weeks, LD50-C decreased by $10 \%$, $10 \%$, which was significantly higher than atorvastatin $10 \mathrm{mg}$, which reduced LDL-C by $39 \%$.

Table 6. Changes in the level of lipoprotein from baseline over 12 weeks with rosuvastatin and atorvastatin $10 \mathrm{mg}$

\begin{tabular}{lll} 
& $\begin{array}{l}\text { Rosuvastatin } 10 \mathrm{mg} \\
(\mathbf{n}=389)\end{array}$ & $\begin{array}{l}\text { Atorvastatin10 } \mathbf{~ m g} \\
(\mathbf{n}=393)\end{array}$ \\
\hline LDL-C & $-46.7^{*}$ & -36.4 \\
HDL-C & 8.9 & 5.5 \\
TC & $-33.0^{*}$ & -26.7 \\
Non-HDL-C & $-42.6^{*}$ & -33.9 \\
TG & -19.2 & -17.6 \\
Apo B & $-36.5^{*}$ & -29.0 \\
Apo A-I & $7.3^{*}$ & 4.1
\end{tabular}

(P<0.001). After 52 weeks, severe LDL-C reduction was observed in patients receiving rosuvastatin compared to those treated with atorvastatin (53\% decrease compared to $44 \%, 0.001 \%$ P) A similar 52 week study of dosage titration compares rosuvastatin with simvastatin and pravastatin. After 12 weeks, LDL$\mathrm{C}$ was decreased by $47.4 \%$ at a dose of $10 \mathrm{mg}$, which is a significant decrease compared to $20 \mathrm{mg}(40 \mathrm{mg} / \mathrm{kg})$ and $20 \mathrm{mg}(0.51 \% \mathrm{P}<0.001)$ of simvastatin $20 \mathrm{mg}(\mathrm{P}$ $<0.001)>\mathrm{P}, 5 / 26 \%$ ) After 52 weeks, a significant decrease of $48 \%$ for LDL-C in patients receiving rosuvastatin compared to those treated with simvastatin $(\mathrm{P}<0.001,37.9 \%)$ and pravastatin $(0.001>\mathrm{P}, 31.6 \%)$ were treated. In the study of statin therapy for high lipid levels versus the dosage of rosuvastatin, rosuvastatin with atorvastatin, simvastatin, and pravastatin were compared at their dose levels to reduce LDL-C levels and their effects on other lipid parameters. (Figure 12).

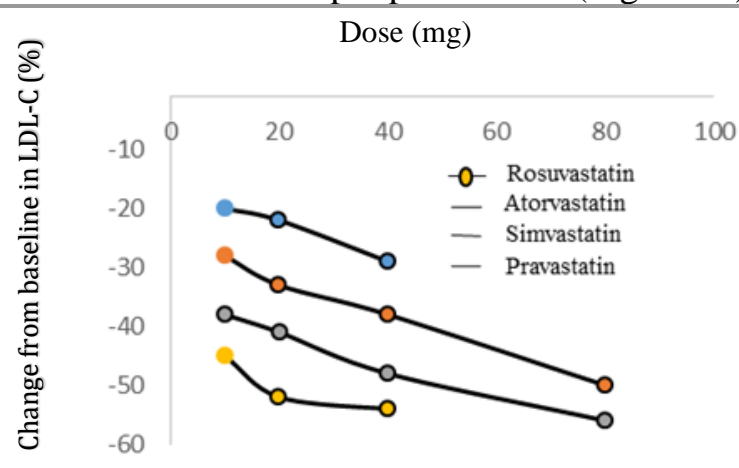

Figure 12. Changes in the percentage of LDL-C from baseline versus dose range for rosuvastatin, atorvastatin, pravastatin and simvastatin

Rosuvastatin $10 \mathrm{mg}$ significantly reduced LDL-C in comparison with atorvastatin $10 \mathrm{mg}$, simvastatin 40-10 $\mathrm{mg}$, pravastatin 40-10 mg. (For all 002/0> P) Given the greater efficacy in reducing LDL-C levels, comparative studies have shown that rosuvastatin allows more patients to achieve LDL-C reduction goals. In the STELLAR study, the proportion of patients receiving $10 \mathrm{mg}$ of rosuvastatin in the $10-\mathrm{mg}$ group of NCEP ATP III was significantly higher than atorvastatintreated patients with a dose of $10 \mathrm{mg}$ and simvastatin and pravastatin at equivalent dosages or higher doses. ( $\mathrm{P}<0.002)$ (Figure 13).

In the study of effective cholesterol-lowering measurements using rosuvastatin-I, the effect of the initial dose of rosuvastatin with conventional doses of atorvastatin, simvastatin, and pravastatin was compared to enable patients to achieve LDL-C targets. 3147 patients with primary hypercholesterolemia and having a history of atherosclerotic, CHD or type 2 diabetes were randomly assigned to receive $10 \mathrm{mg}$ of rosuvastatin, 10 or $20 \mathrm{mg}$ of atorvastatin, $20 \mathrm{mg}$ of simvastatin, or $40 \mathrm{mg}$ of pravastatin for 8 weeks (Figure 14).

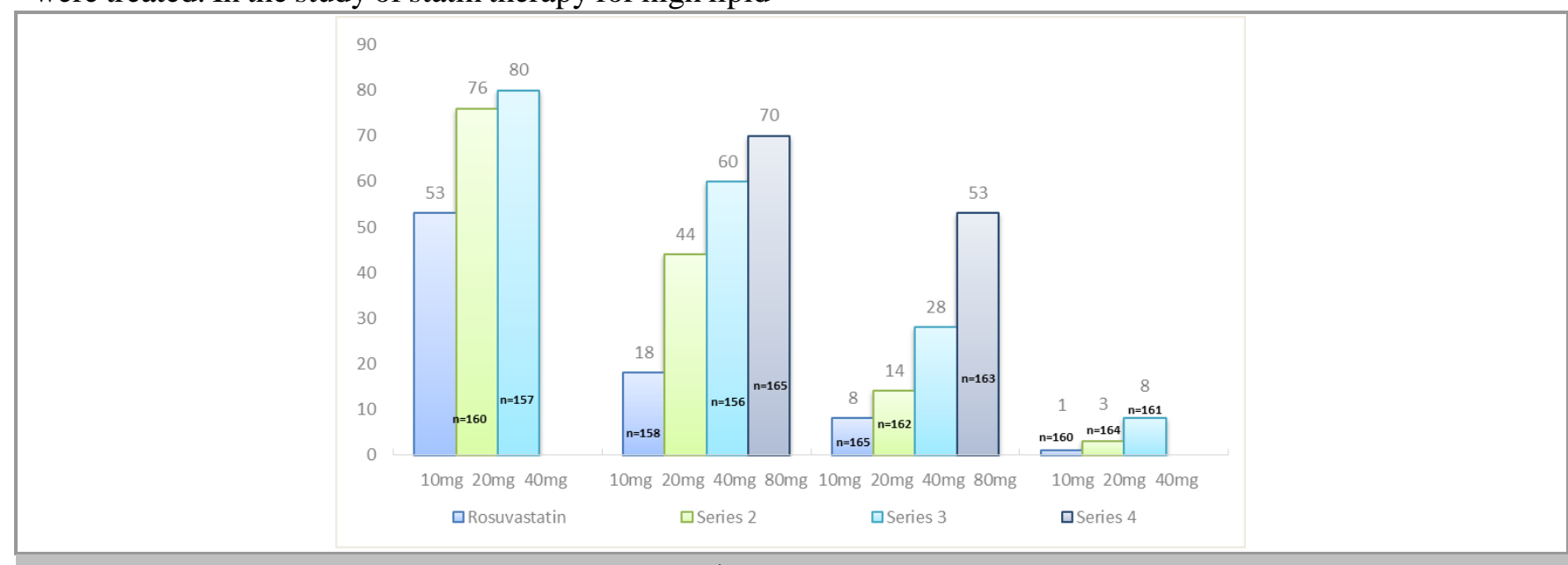

Figure 13. Low-density lipoprotein cholesterol (LDL-C) (less than $2.6 \mathrm{mmol} / \mathrm{L}$ ) cholesterol after 8 weeks of treatmen 


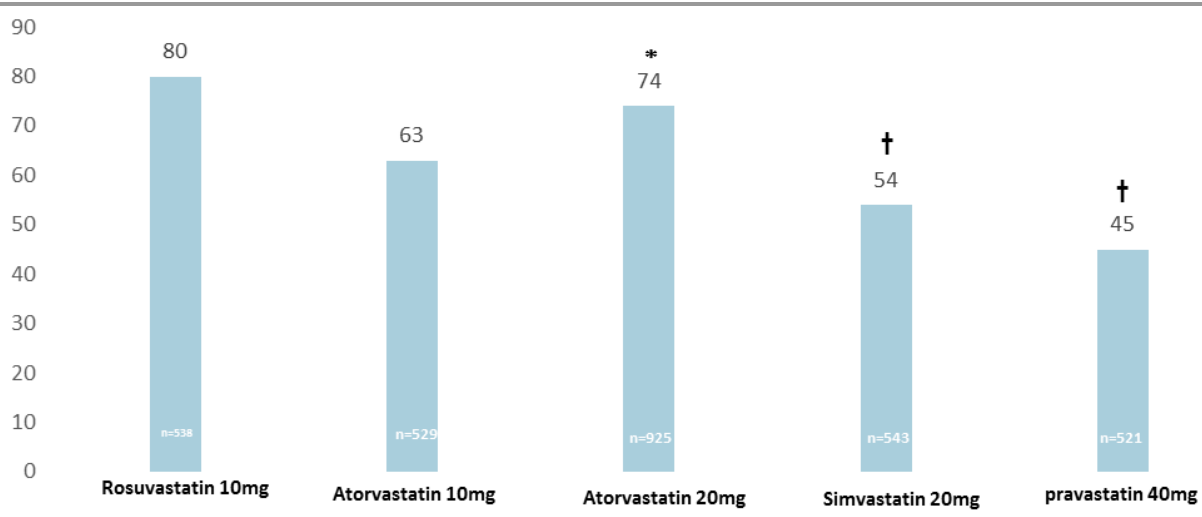

Figure 14. Low-density lipoprotein cholesterol (LDL-C) (less than $2.6 \mathrm{mmol} / \mathrm{L}$ ) cholesterol after 8 weeks of treatmen

Recently, European guidelines for the prevention of cardiovascular disease have been updated and lower targets for LDL-C of less than $2.5 \mathrm{mg} / \mathrm{L}$ and total cholesterol (TC) of less than $4.5 \mathrm{mg} / \mathrm{L}$ than those with the highest risk Cardiovascular disease, including those with clinical evidence of atherosclerosis and patients with diabetes, is recommended. In addition, studies have compared the effectiveness of rosuvastatin and atorvastatin to diabetic patients for the purposes of European cholesterol. For example, the ANDROMEDA study in the UK has examined the effects of rosuvastatin 20-20 mg and atorvastatin 10 $20 \mathrm{mg}$ for about 500 patients with type 2 diabetes. Patients randomized to receive rosuvastatin $10 \mathrm{mg}$ and atorvastatin $10 \mathrm{mg}$ for a period of 8 weeks followed by doses up to $20 \mathrm{mg}$ for the next 8 weeks, significantly increased in patients treated with rosuvastatin compared to atorvastatin in both of the 8 week courses (94 versus 79\%, $\mathrm{P}<0.001)$ and 16 weeks (96\% versus $87 \%, \mathrm{P}=0.002$ ) had LDL-C targets (less than 2.5 $\mathrm{mmol} / \mathrm{L})$ Achieved.

\subsubsection{Improvements across the lipid profile}

The use of other components of the lipid profile is increasingly important as indicators of the risk of cardiovascular disease. Low levels of high-density lipoprotein cholesterol are known to be the main risk factor for NCEP ATP III and European guidelines. In the MERCURY I study, rosuvastatin $10 \mathrm{mg}$ compared to atorvastatin $10 \mathrm{mg}$ increased HDL-C levels 9.2\%, which was $6.8 \%$ for atorvastatin. ( $\mathrm{P}<0.01)$. In addition, for simvastatin $20 \mathrm{mg}$ and $0.8 \%$ Pravastatin $40 \mathrm{mg}$, an increase wasSimvastatin $20 \mathrm{mg}$ and $0.8 \%$ Pravastatin $40 \mathrm{mg}$, an increase was observed in $6.7 \mathrm{HDL}-\mathrm{C}$ levels.Also, in analyzes of studies in patients with hypercholesterolemia, $10 \mathrm{mg}$ of rosuvastatin significantly increases HDL-C levels more than $10 \mathrm{mg}$ atorvastatin, $20 \mathrm{mg}$ simvastatin, $20 \mathrm{mg}$ pravastatin. (Figure 12 and 13). Increased levels of triglyceride (TG) are associated with an increased risk of CVD, which has a high triglyceride-rich lipoprotein, such as very low-density lipoprotein (VLDL), effective in the formation of fat deposits in the arteries. The NCEP ATP III guidelines are known as a collection of LDL$\mathrm{C}$ and VLDL-C and are referred to as secondary therapies for treating people with high triglyceride levels, called HDL-Cs (TCs, minus HDL-Cs).

In a combined analysis, rosuvastatin $10 \mathrm{mg}$ compared to atorvastatin $10 \mathrm{mg}(\mathrm{P}<0.001)$ was more effective in reducing non-HDL-C and had similar effects with atorvastatin on triglyceride levels (Table 6).

Epidemiological studies have shown that apolipoprotein) B, a component of LDL-C, is associated with a high risk of developing cardiovascular disease. On the other hand, the main apolipoprotein A-I with HDL-C is a negative factor in the risk of heart disease. Rosuvastatin $10 \mathrm{mg}$ significantly reduced the apolipoprotein $\mathrm{B}$ level in comparison with atorvastatin $10 \mathrm{mg}$, simvastatin and pravastatin $20 \mathrm{mg}(\mathrm{P}<0.001)$ (Table 6 and 7).Also, a significant reduction in apolipoprotein B/A-I ratio was observed for rosuvastatin $10 \mathrm{mg}$ compared to atorvastatin $10 \mathrm{mg}$, simvastatin and pravastatin $20 \mathrm{mg}$ ( $40 \%$ versus $31 \%, 30 \%$, and $23 \%$ respectively, $\mathrm{P}$ $<0.001)$.

Table 7. Changes in the level of lipoprotein from baseline over 12 weeks with rosuvastatin $10 \mathrm{mg}$, simvastatin, and pravastatin $20 \mathrm{mg}$

\begin{tabular}{|c|c|c|c|}
\hline & $\begin{array}{l}\text { Rosuvastatin } \\
10 \mathrm{mg} \\
(\mathrm{n}=\mathbf{2 2 6})\end{array}$ & $\begin{array}{l}\text { Simvastatin } \\
20 \mathrm{mg} \\
(\mathrm{n}=249)\end{array}$ & $\begin{array}{l}\text { Pravastatin } \\
20 \mathrm{mg} \\
(\mathrm{n}=252)\end{array}$ \\
\hline LDL-C & $-48.1 \dagger$ & -35.7 & -27.1 \\
\hline HDL-C & $9.1^{*}$ & 6.2 & 6.2 \\
\hline TC & $-34.0 t$ & -25.1 & -19.2 \\
\hline Non-HDL-C & $-44.0 \dagger$ & -32.5 & -25.0 \\
\hline TG & -20.21 & -12.2 & -12.4 \\
\hline Apo B & $-30.9 \ddagger$ & -28.0 & -20.6 \\
\hline Apo A-I & 5.3 & 4.8 & 4.2 \\
\hline
\end{tabular}




\subsubsection{Safety}

Statins are an acceptable drug category. Although recent press attention has focused on the statins' safety profile, the unpleasant events caused by these drugs are rare and rare. The safety of rosuvastatin has been studied in over 20,000 patients with a wide range of dyslipidemia types as well as elderly patients, patients with renal dysfunction, high blood pressure, cardiovascular disease, and diabetes. Data from fixeddose controlled trials showed that rosuvastatin has a mild state of events similar to other statins. $(2.9 \%$ for rosuvastatin $10-40 \mathrm{mg}$ ) [n=3074], $3.2 \%$ for atorvastatin $10-80 \mathrm{mg}$ [ $\mathrm{n}=2899$ ], $2.5 \%$ for simvastatin $80-100 \mathrm{mg}$ [ $\mathrm{n}=1457], 2.5 \%$ for pravastatin $10-40 \mathrm{mg}$ [ $\mathrm{n}=1278]$ ). The most common side effects associated with treatment with rosuvastatin in the clinical trial program were muscle aches, weakness, nausea, abdominal pain. These precursors were similar to other statins and were generally mild and transient in severity. Most of the worries about the side effects of statins are liver and muscle damage. In controlled clinical trials, a significant increase in alanine aminotransferase (ALT) (more than 3 times the normal upper limit) in $0.2 \%$ of patients receiving rosuvastatin $[\mathrm{n}=8190]$, atorvastatin [ $\mathrm{n}=3749]$, simvastatin $[\mathrm{n}=2398]$, pravastatin $[\mathrm{n}=1260]$ occurred. In the dose range of $10-40 \mathrm{mg}$, myopathy (creatine kinase levels more than 10 times the normal upper limit, with muscle damage symptoms not explained by exercise and ulcers) was less than $0.1 \%$ with rosuvastatin, which is similar to that reported in statins It was different. Commonly, rosuvastatin, like pravastatin, is relatively hydrophilic; hydrophilic statins are less likely to cause muscular complications than those with high blood levels of statins. During a controlled trial, few patients treated with statin drugs showed proteinuria. Changes in urine protein from low and low initially to +2 or more in the final study were similar in patients treated with rosuvastatin $5-40 \mathrm{mg}$, atorvastatin $10-80 \mathrm{mg}$, simvastatin $20-80 \mathrm{mg}$, pravastatin $20-40 \mathrm{mg}$ and placebo. Was the analysis of electrophoresis shows that proteinuria created by a statin is compatible with the "tube" (by reducing the absorption of the filtered proteins normally), instead of "glomerulus" (Increased albumin leakage and larger proteins). Additionally, serum creatinine level in patients receiving rosuvastatin $40-40 \mathrm{mg}$ and other statins in comparison to that for about 8 weeks was essentially unchanged. Similar findings were observed in patients with long-term exposure to rosuvastatin (less than or equal to 48 or 96 weeks) and in those with mild to moderate renal impairment, as defined by creatinine withdrawal. Safety of rosuvastatin was observed with progressive observations, namely glomerular clearance in patients receiving rosuvastatin after a long-term treatment period (greater than 96 weeks).

\subsubsection{Expert opinion}

As evidence of the use of statin in treatment is strongly supported and increased, and the population of patients eligible for statin therapy expands, the need for more effective factors will increase. In terms of LDL-C reduction, rosuvastatin is an improvement over other statins. Effective reduction in LDL-C with rosuvastatin, even at an initial dose of $10 \mathrm{mg}$, should help to achieve goals while reducing the need for dose stabilization. The need to use higher doses in other statins to reach patients for the desired target can also be done by changing the dosage of rosuvastatin to the initial dose. In addition, the effects of rosuvastatin on the reduction of other fatty-type elements such as HDL$\mathrm{C}$, non-HDL-C and TG may reduce the risk of CHD beyond the lower limit of LDL-C. This will be helpful in patients with mixed dyslipidemia, diabetes or metabolic syndrome. More effective in preventing LDL-C and improving the level of fat components may also reduce the need for combined therapy in some patients. The safety profile of rosuvastatin is similar to other statins. At present, there is limited clinical data to show how pitavastatin is compared with existing statins.

\section{Conclusion}

Evidence from extensive studies suggests that statin therapy may reduce the risk of coronary artery disease by 3 to 6 years by $20-40 \%$.

In addition to altering lipid profile, statins have cholesterol-independent pleiotropic effects that are useful in reducing the risk of CVD. The contribution of these effects on reducing the events has not yet been fully understood and it has not yet been established that new statins have the potential to increase the potential of pleotherapy effects. Nitric oxide appears to be an important intermediate in some of the pleotherapy effects of statins. Although the benefits of statin therapy have been shown in a wide range of patients, these drugs can also have side effects. The most serious side effect is in people taking other medications or those who have a health condition. The most common side effects of statins are the muscle and joint pain that can also cause nausea and vomiting. The most serious side effects include kidney and liver damage, increased blood sugar, and neurological side effects. In some people, statin can cause muscle cell failure, resulting in permanent muscle damage. If your statin is not a good option or complications, your doctor may prescribe a different drug for treating high cholesterol. A good alternative is cholesterol absorption inhibitor. This medication can properly prevent the absorption of cholesterol from your small intestine. If you cannot 
absorb corrodes, it cannot reach your bloodstream. The only drug in the pharmacies is ezetimibe (zetia $\left.{ }^{\circledR}\right)$. This drug can be combined with statin to give a faster result, although many physicians prescribe thymine alone and combine it with a low-fat diet to help lower cholesterol. Alternatives to other bile grafting resins or complexing agents, these medications act through your bile duct and block your cholesterol in your bloodstream. These drugs are among the oldest blood cholesterol-lowering drugs and are not effective in other drugs, and are used for people with cholesterol just a little too normal. The International Health Insurance Organization has approved the use of new cholesterol-lowering drugs that are as effective as statins. Praluent and Repatha are two of the leading vendors in discovering the new type of dermalogy that is expected to halve the level of bad cholesterol in patients. Approximately 325,000 patients may receive these medications within a few weeks after approval by the National Institute of Clinical Nutrition and Clinical Supremacy. In addition, these drugs are effective for those who have high cholesterol levels or who have heart disease that cannot withstand the side effects of statins. The strains that are consumed daily by more than 7 million people in the UK expanded 30 years ago. However, they were known for their side effects, such as muscle aches. It is estimated that more than $20 \%$ of patients who have statins cause muscle tension in their bodies, are forced to stop using it and therefore are at high risk for heart attack and stroke. Professor Garval Langson, the NICE director, said: "We are very pleased to be able to introduce two new drugs and alternatives to the statins, the names of Alirocumab and Evolocumab. These new drugs are readily available for about 200,000 people who are not using statins, and can be easily accessed for approximately 125,000 patients who cannot lower their cholesterol levels through their statins.

\section{Acknowledgment}

I would like to thank Dr. Mohammad G. Dekamin as my Master's Supervisor for completing my Masters Degree. I would also like to thank Dr. Hoda Hamidi for her patience in addressing the shortcomings of the article.

\section{Disclosure statement}

No potential conflict of interest was reported by the authors.

\section{References}

[1] Winslow, R. (2000). Birth of a blockbuster: Lipitor's unlikely route out of the lab. Wall Street Journal, 24.

[2] Endo, A. (1992). The discovery and development of HMG-CoA reductase inhibitors. Journal of lipid research, 33(11), 1569-1582.
[3] Rosa, G. M., Carbone, F., Parodi, A., Massimelli, E. A., Brunelli, C., Mach, F., ... \& Montecucco, F. (2014). Update on the efficacy of statin treatment in acute coronary syndromes. European journal of clinical investigation, 44(5), 501-515.

[4] Hongbao, M., \& Yan, Y. Streptozotocin, Atorvastatin, Renal, Diabetes and Related Factors.

[5] Adams, S. P., Tsang, M., \& Wright, J. M. (2012). Lipid lowering efficacy of atorvastatin. Cochrane database of systematic reviews, (12).

[6] Hermann, M., Bogsrud, M. P., Molden, E., Åsberg, A., Mohebi, B. U., Ose, L., \& Retterstøl, K. (2006). Exposure of atorvastatin is unchanged but lactone and acid metabolites are increased several-fold in patients with atorvastatin-induced myopathy. Clinical Pharmacology \& Therapeutics, 79(6), 532-539.

[7] Christians, U., Jacobsen, W., \& Floren, L. C. (1998). Metabolism and drug interactions of 3hydroxy-3-methylglutaryl coenzyme A reductase inhibitors in transplant patients: are the statins mechanistically similar?. Pharmacology \& therapeutics, 80(1), 1-34.

[8] Tobert, J. A. (2003). Lovastatin and beyond: the history of the HMG-CoA reductase inhibitors. Nature reviews Drug discovery, 2(7), 517.

[9] Macedo, A. F., Taylor, F. C., Casas, J. P., Adler, A., Prieto-Merino, D., \& Ebrahim, S. (2014). Unintended effects of statins from observational studies in the general population: systematic review and meta-analysis. BMC medicine, 12(1), 51.

[10] Roche, V. F. (2005). Antihyperlipidemic statins: a self-contained, clinically relevant medicinal chemistry lesson. American Journal of Pharmaceutical Education, 69(4), 77.

[11] Istvan, E. S., \& Deisenhofer, J. (2001). Structural mechanism for statin inhibition of HMG-CoA reductase. Science, 292(5519), 11601164.

[12] Shepherd, J., Hunninghake, D. B., Barter, P., McKenney, J. M., \& Hutchinson, H. G. (2003). Guidelines for lowering lipids to reduce coronary artery disease risk: a comparison of rosuvastatin with atorvastatin, pravastatin, and simvastatin for achieving lipid-lowering goals. The American journal of cardiology, 91(5), 11-17.

[13] Liu, J., Zhang, J., Shi, Y., Grimsgaard, S., Alraek, T., \& Fønnebø, V. (2006). Chinese red yeast rice (Monascus purpureus) for primary hyperlipidemia: a meta-analysis of randomized controlled trials. Chinese medicine, 1(1), 4 .

[14] Daugherty, M., Polanuyer, B., Farrell, M., Scholle, M., Lykidis, A., de Crécy-Lagard, V., \& Osterman, A. (2002). Complete reconstitution of 
the human coenzyme A biosynthetic pathway via comparative genomics. Journal of Biological Chemistry, 277(24), 21431-21439.

[15] Bachhawat, B. K., Austin, J., \& Armstrong, D. (2015). A Cerebroside Sulphotransferase Deficiency in a Human Disorder of Myelin. The National medical journal of India, 28(3), 161-164.

[16] Surolia, A. (1997). An outstanding scientist and a splendid human being: Prof Bimal Kumar Bachhawat. Glycobiology, 7(4), R5-R6.

[17] Stancu, C., \& Sima, A. (2001). Statins: mechanism of action and effects. Journal of cellular and molecular medicine, 5(4), 378-387.

[18] Puccetti, L., Pasqui, A. L., Pastorelli, M., Bova, G., Cercignani, M., Palazzuoli, A., ... \& Bruni, F. (2002). Time-dependent effect of statins on platelet function in hypercholesterolaemia. European journal of clinical investigation, 32(12), 901-908.

[19] Roth, B. D. (2002). 1 The Discovery and Development of Atorvastatin, a Potent Novel Hypolipidemic Agent. In Progress in medicinal chemistry (Vol. 40, pp. 1-22). Elsevier.

[20] Miziorko, H. M. (2011). Enzymes of the mevalonate pathway of isoprenoid biosynthesis. Archives of biochemistry and biophysics, 505(2), 131-143.

[21] Frantz Jr, I. D., \& Schroepfer Jr, G. J. (1967). Sterol biosynthesis. Annual review of biochemistry, 36(1), 691-726.

[22] Hosokawa, G., Patterson, G. W., \& Lusby, W. R. (1984). Effects of triarimol, tridermorph and triparanol on sterol biosynthesis in carrot, tobacco and soybean suspension cultures. Lipids, 19(6), 449-456.

[23] Singh, P., Saxena, R., Srinivas, G., Pande, G., \& Chattopadhyay, A. (2013). Cholesterol biosynthesis and homeostasis in regulation of the cell cycle. PloS one, 8(3), e58833.

[24] BEYER, R. S., \& JENSEN, L. S. (1993). The hypocholesterolemic agent dichloroacetate increases egg cholesterol content of laying hens. Poultry science, 72(6), 1063-1069.

[25] Boots, M. R., Boots, S. G., Noble, C. M., \& Guyer, K. E. (1973). Hypocholesterolemic Agents II: Inhibition of $\beta$-Hydroxy- $\beta$-methylglutaryl Coenzyme A Reductase by Arylalkyl Hydrogen Succinates and Glutarates. Journal of pharmaceutical sciences, 62(6), 952-957.

[26] Brown, A. G., Smale, T. C., King, T. J., Hasenkamp, R., \& Thompson, R. H. (1976). Crystal and molecular structure of compactin, a new antifungal metabolite from Penicillium brevicompactum. Journal of the Chemical Society, Perkin Transactions 1, (11), 1165-1170.

[27] Endo, A., Tsujita, Y., Kuroda, M., \& TANZAWA, K. (1977). Inhibition of Cholesterol
Synthesis in vitro and in vivo by ML-236A and ML-236B, Competitive Inhibitors of 3-Hydroxy-3methylglutaryl-Coenzyme A Reductase. European Journal of Biochemistry, 77(1), 31-36.

[28] Alberts, A. W., Chen, J., Kuron, G., Hunt, V., Huff, J., Hoffman, C., ... \& Patchett, A. (1980). Mevinolin: a highly potent competitive inhibitor of hydroxymethylglutaryl-coenzyme A reductase and a cholesterol-lowering agent. Proceedings of the National Academy of Sciences, 77(7), 3957-3961.

[29] Endo, A. (1979). Monacolin K, a new hypocholesterolemic agent produced by a Monascus species. The Journal of antibiotics, 32(8), 852-854..

[30] Hoffman, W. F., Alberts, A. W., Anderson, P. S., Chen, J. S., Smith, R. L., \& Willard, A. K. (1986). 3-Hydroxy-3-methylglutaryl-coenzyme A reductase inhibitors. 4. Side-chain ester derivatives of mevinolin. Journal of medicinal chemistry, 29(5), 849-852.

[31] Paal, C. (1885). Synthese von Thiophen-und Pyrrolderivaten. Berichte der deutschen chemischen Gesellschaft, 18(1), 367-371.

[32] Narasaka, K., \& Pai, H. C. (1980). Stereoselective synthesis of meso (or erythro) 1, 3diols from $\beta$-hydroxyketones. Chemistry Letters, 9(11), 1415-1418.

[33] Rádl, S., Stach, J., \& Hajicek, J. (2002). An improved synthesis of 1, 1-dimethylethyl 6cyanomethyl-2, 2-dimethyl-1, 3-dioxane-4acetate, a key intermediate for atorvastatin synthesis. Tetrahedron letters, 43(11), 2087-2090.

[34] Bodurow, C. C., Boyer, B. D., Brennan, J., Bunnell, C. A., Burks, J. E., Carr, M. A., ... \& Graves, B. J. (1989). An enantioselective synthesis of loracarbef (LY163892/KT3777). Tetrahedron Letters, 30(18), 2321-2324.

[35] Hu, F. B., Stampfer, M. J., Manson, J. E., Rimm, E., Colditz, G. A., Rosner, B. A., ... \& Willett, W. C. (1997). Dietary fat intake and the risk of coronary heart disease in women. New England journal of medicine, 337(21), 1491-1499.

[36] Chen, K. M., Hardtmann, G. E., Prasad, K., Repič, O., \& Shapiro, M. J. (1987). 1, 3-syn diastereoselective reduction of $\beta$-hydroxyketones utilizing alkoxydialkylboranes. Tetrahedron letters, 28(2), 155-158.

[37] Kumar, P., Deshmukh, A. N., Upadhyay, R. K., \& Gurjar, M. K. (2005). A simple and practical approach to enantiomerically pure (S)-3-hydroxy$\gamma$-butyrolactone: synthesis of (R)-4-cyano-3hydroxybutyric acid ethyl ester. Tetrahedron: Asymmetry, 16(16), 2717-2721.

[38] Pfruender, H., Amidjojo, M., Hang, F., \& Weuster-Botz, D. (2005). Production of Lactobacillus kefir cells for asymmetric synthesis 
of a 3, 5-dihydroxycarboxylate. Applied microbiology and biotechnology, 67(5), 619-622.

[39] Patel, R. N., Banerjee, A., McNamee, C. G., Brzozowski, D., Hanson, R. L., \& Szarka, L. J. (1993). Enantioselective microbial reduction of 3 , 5-dioxo-6-(benzyloxy) hexanoic acid, ethyl ester. Enzyme and microbial technology, 15(12), 1014-1021.

[40] Wolberg, M., Hummel, W., Wandrey, C., \& Müller, M. (2000). Highly regio-and enantioselective reduction of 3, 5dioxocarboxylates. Angewandte Chemie International Edition, 39(23), 4306-4308.

[41] Gijsen, H. J., \& Wong, C. H. (1994). Unprecedented asymmetric aldol reactions with three aldehyde substrates catalyzed by 2deoxyribose-5-phosphate aldolase. Journal of the American Chemical Society, 116(18), 8422-8423.

[42] Liu, J., Hsu, C. C., \& Wong, C. H. (2004). Sequential aldol condensation catalyzed by DERA mutant Ser238Asp and a formal total synthesis of atorvastatin. Tetrahedron letters, 45(11), 24392441.

[43] Greenberg, W. A., Varvak, A., Hanson, S. R., Wong, K., Huang, H., Chen, P., \& Burk, M. J. (2004). Development of an efficient, scalable, aldolase-catalyzed process for enantioselective synthesis of statin intermediates. Proceedings of the National Academy of Sciences, 101(16), 57885793.

[44] DeSantis, G., Zhu, Z., Greenberg, W. A., Wong, K., Chaplin, J., Hanson, S. R., ... \& Robertson, D. E. (2002). An enzyme library approach to biocatalysis: development of nitrilases for enantioselective production of carboxylic acid derivatives. Journal of the American Chemical Society, 124(31), 9024-9025.

[45] DeSantis, G., Wong, K., Farwell, B., Chatman, K., Zhu, Z., Tomlinson, G., ... \& Kretz, K. (2003). Creation of a productive, highly enantioselective nitrilase through gene site saturation mutagenesis (GSSM). Journal of the American Chemical Society, 125(38), 11476-11477.

[46] Short, J. M. (2001). U.S. Patent No. 6,171,820. Washington, DC: U.S. Patent and Trademark Office.

[47] Bergeron, S., Chaplin, D. A., Edwards, J. H., \& Ellis, B. S. (2006). W., Hill CL, Holt-Tiffin K., Knight JR, Mahoney T., Osborne AP, Ruecroft G. Org. Proc. Res. Dev, 10, 661.

[48] Sun, F., Xu, G., Wu, J., \& Yang, L. (2006). Efficient lipase-catalyzed kinetic resolution of 4arylmethoxy-3-hydroxybutanenitriles: application to an expedient synthesis of a statin intermediate. Tetrahedron: Asymmetry, 17(20), 2907-2913.
[49] Wang, G., \& Hollingsworth, R. I. (1999). Synthetic routes to L-carnitine and L-gammaamino-beta-hydroxybutyric acid from (S)-3hydroxybutyrolactone by functional group priority switching. Tetrahedron: Asymmetry, 10(10), 18951901.

[50] Lee, S. H., Park, O. J., \& Uh, H. S. (2008). A chemoenzymatic approach to the synthesis of enantiomerically pure (S)-3-hydroxy- $\gamma$ butyrolactone. Applied microbiology and biotechnology, 79(3), 355-362.

[51] Goldberg, S., Guo, Z., Chen, S., Goswami, A., \& Patel, R. N. (2008). Synthesis of ethyl-(3R, 5S)dihydroxy-6-benzyloxyhexanoates via diastereoand enantioselective microbial reduction: Cloning and expression of ketoreductase III from Acinetobacter sp. SC 13874. Enzyme and Microbial Technology, 43(7), 544-549.

[52] Majerić Elenkov, M., Tang, L., Hauer, B., \& Janssen, D. B. (2006). Sequential kinetic resolution catalyzed by halohydrin dehalogenase. Organic letters, 8(19), 4227-4229.

[53] Patel, J. M. (2009). Biocatalytic synthesis of atorvastatin intermediates. Journal of Molecular Catalysis B: Enzymatic, 61(3-4), 123-128.

[54] Hu, L., Xiong, F., Chen, X., Chen, W., He, Q., \& Chen, F. (2013). Synthetic studies on statins. Part 1: a short and cyanide-free synthesis of atorvastatin calcium via an enantioselective aldol strategy. Tetrahedron: Asymmetry, 24(4), 207-211.

[55] Su, Z., Wen, J., Dente, L., Velde, R. V. D., Wang, L., Ma, Y., ... \& Hu, Z. (2011). The Tibetan Plateau observatory of plateau scale soil moisture and soil temperature (Tibet-Obs) for quantifying uncertainties in coarse resolution satellite and model products. Hydrology and earth system sciences, 15(7), 2303-2316.

[56] Brower, P. L., Butler, D. E., Deering, C. F., Le, T. V., Millar, A., Nanninga, T. N., \& Roth, B. D. (1992). The synthesis of (4R-cis)-1, 1dimethylethyl 6-cyanomethyl-2, 2-dimethyl-1, 3dioxane-4-acetate, a key intermediate for the preparation of CI-981, a highly potent, tissue selective inhibitor of HMG-CoA reductase. Tetrahedron Letters, 33(17), 2279. 2282.

[57] Trost, B. M., \& Brindle, C. S. (2010). The direct catalytic asymmetric aldol reaction. Chemical Society Reviews, 39(5), 16001632.

[58] Liuzzo, G., Biasucci, L. M., Gallimore, J. R., Grillo, R. L., Rebuzzi, A. G., Pepys, M. B., \& Maseri, A. (1994). The prognostic value of Creactive protein and serum amyloid a protein in severe unstable angina. New England journal of medicine, 331(7), 417-424. 
[59] Narasaka, K., \& Pai, F. C. (1984). Stereoselective reduction of $\beta$ hydroxyketones to 1 , 3-diols highly selective 1, 3-asymmetric induction via boron chelates. Tetrahedron, 40(12), 22332238.

[60] Black, D. M., Bakker-Arkema, R. G., \& Nawrocki, J. W. (1998). An overview of the clinical safety profile of atorvastatin (Lipitor), a new HMG-CoA reductase inhibitor. Archives of internal Medicine, 158(6), 577-584.

[61] Maron, D. J., Fazio, S., \& Linton, M. F. (2000). Current perspectives

statins. Circulation, 101(2), 207-213.

[62] Rosenson, R. S. (2004). Statins: can the new generation make an impression?. Expert opinion on emerging drugs, 9(2), 269-279.

[63] Ballantyne, C. M. (1998). Low-density lipoproteins and risk for coronary artery disease. The American journal of cardiology, 82(8), 3-12.

[64] Olsson, A. G., Pauciullo, P., Soska, V., Luley, C., Pieters, R. E., Broda, G., ... \& Fluvastatin Study Group. (2001). Comparison of the efficacy and tolerability of fluvastatin extended-release and immediate-release formulations in the treatment of primary hypercholesterolemia: a randomized trial. Clinical therapeutics, 23(1), 45-61.

[65] Toth, P. P., Worthy, G., Gandra, S. R., Sattar, N., Bray, S., Cheng, L. I., ... \& Deshpande, S. (2017). Systematic review and network metaanalysis on the efficacy of evolocumab and other therapies for the management of lipid levels in hyperlipidemia. Journal of the American Heart Association, 6(10), e005367.

How to cite this manuscript: Sajedeh Safapoor, Hamid Yazdani, Parisa Shahabi, A Review on Synthesis and Applications of Statin Family Drugs as a New Generations of Anti-Blood Medicines, Journal of Chemical Reviews, 2020, 2(1), 1-27. 